\title{
Embodiment in physics learning: A social-semiotic look
}

\author{
Elias Euler, ${ }^{1, *}$ Elmer Rådahl, ${ }^{2}$ and Bor Gregorcic ${ }^{1}$ \\ ${ }^{1}$ Department of Physics and Astronomy, Uppsala University, Box 516, 75120 Uppsala, Sweden \\ ${ }^{2}$ Dragonskolan, Dragongatan 1, 903 22, Umeå, Sweden
}

(Received 22 January 2019; published 30 May 2019)

\begin{abstract}
In this paper, we present a case study of a pair of students as they use nondisciplinary communicative practices to mechanistically reason about binary star dynamics. To do so, we first review and bring together the theoretical perspectives of social semiotics and embodied cognition, therein developing a new methodological approach for analyzing student interactions during the learning of physics (particularly for those interactions involving students' bodies). Through the use of our new approach, we are able to show how students combine a diverse range of meaning-making resources into complex, enacted analogies, thus forming explanatory models that are grounded in embodied intuition. We reflect on how meaning-making resources — even when not physically persistent—can act as coordinating hubs for other resources as well as how we might further nuance the academic conversation around the role of the body in physics learning.
\end{abstract}

DOI: 10.1103/PhysRevPhysEducRes.15.010134

\section{INTRODUCTION}

Learning physics, as with learning other sciences, involves developing the ability to use the discipline's "discourse" [1,2] as part of the process of enculturation into a community of practice $[3,4]$. Within a socialsemiotic perspective of learning [5,6] (expanded upon later), students of physics might be expected to develop fluency in disciplinary discourse by continually "test[ing] out words and practices" until their expressions more closely resemble that of physics experts [7] (p. 4). This means that students will likely spend time using colloquial discourse as they navigate and make sense of the language and practices of the physics community. Nonetheless, an acknowledgement of students' use of nondisciplinary discourse need not be synonymous with a concession that students will be doing 'bad' physics. Students are likely to benefit from making use of everyday language as a means of preparing the conceptual terrain and motivating the need for formal definitions of disciplinary concepts (e.g., [8-10]). A skilled educator will recognize and respond to student-formulated ideas [11] in a manner that helps students proceed toward more disciplinary understandings.

However, research has shown that, in addition to resources such as mathematical formalisms and spoken language, physics students also often recruit other resources such as

*elias.euler@physics.uu.se

Published by the American Physical Society under the terms of the Creative Commons Attribution 4.0 International license. Further distribution of this work must maintain attribution to the author(s) and the published article's title, journal citation, and DOI. gestures and manipulations of their surroundings to make meaning. For example, Gregorcic et al. [12] provide an analysis that shows how small groups of students described patterns, proposed experiments, and predicted outcomes in a sciencelike manner, all while using "hand waving," manipulations of a large touch-screen, and informal vocabulary. The study provides an example of students producing qualitative descriptions of orbital motion akin to Kepler's laws, showing that nondisciplinary meaning-making resources can manifest conceptual and procedural ideas that are worthwhile from a physics disciplinary perspective.

However, while Ref. [12] illustrates how students can arrive at descriptions of orbital motion through spontaneous, informal means, it remains relatively unexplored how students might recruit a similar interplay of meaning-making resources to develop explanations of similar phenomena. To address this unexplored aspect, our investigation presented in this paper builds on Ref. [12]. This is because we see the topic of orbital motion explored by Gregorcic et al. as particularly apt for highlighting the distinction between descriptive and explanatory models in physics [13]. Historically, Kepler's laws constitute a descriptive model for the motion of planets around the Sun, while Newton's laws of motion and his law of universal gravitation provide an explanatory model of the same phenomenon [14]. We aim to investigate how students' nondisciplinary meaningmaking resembles the latter, insofar as the students come to not only describe what happens, but also explain why it happens the way it does.

To do so, we present a case study of two students as they explore a feature of orbital motion with the PhET simulation software, My Solar System [15], on an interactive whiteboard (IWB). We find that the students incorporate their bodily experience and enact a metaphor, namely, a 
two person dance which resembles the spinning dance done by Jack and Rose in the movie Titanic [16], in order to communicate and reason mechanistically about the dynamics of a binary star system. We take mechanistic reasoning to mean reasoning that involves explanations of phenomena in terms of cause and effect mechanism-that is reasoning about why and how (see Ref. [17] for an in-depth discussion of the topic). We show how the pair of students address a question by utilizing a diverse set of embodied, interpersonal, and largely nondisciplinary meaning-making resources, yet do so in a manner which fruitfully relates to a disciplinary treatment of the topic. In this way, we see our study contributing to scholarly work on how students' bodies can play a role in the learning of physics. That is, we show how students can coordinate multimodal $[18,19]$ sets of meaning-making actions as part of enacted metaphors.

As part of our analysis, we use a combination of two theoretical perspectives, both of which have been shown on their own to be useful ways of viewing meaning making. The first, social semiotics, examines how meaningmaking resources - such as the conversational resources of talk, gesture, touch, and body position, but also the (typically) disciplinary resources of mathematical equations and canonical physical laws - combine to afford various meaning potentials in social contexts. The second, embodied cognition, is interested in how thinking can be interpreted as an act of metaphorically directed construction from elementary, experientially gleaned cognitive building blocks. Drawing from these two theoretical traditions, we aim to address the following research question:

How do two high school students make use of nondisciplinary meaning-making resources to mechanistically reason about binary star dynamics in ways that relate to aspects deemed relevant by the physics discipline?

Our paper provides a detailed account of how students' bodies can play a central role in their scientific meaning making, particularly as the students engage in mechanistic reasoning. In doing so, we contribute to academic discussions around students' nondisciplinary meaning making and embodiment in physics learning. Our analysis shows how students can utilize their bodies not only as the loci of gestural and tactile expressions but also as representations of physical phenomena in the enactment of analogies (i.e., an enacted two-person dance as an analogue to a binary star system).

While existing physics education research (PER) has separately attended to patterns of socially constructed meaning [5,12,20,21], the role of students' bodies in learning activities [7,22-24], and the character of students' mechanistic reasoning [17], a combination of these interests remains scarcely explored, especially within the context of physics and astronomy learning. In an effort to advance the theoretical discussion across these areas of interest, our methodology brings together the perspectives of social semiotics and embodied cognition, ultimately providing the interested education researcher with a new analytic approach for investigating student interaction. We attend to segments of video data containing students' mechanistic reasoning through a chain of interpretations: first, we observe the students' use of a multimodal array of predominantly nondisciplinary meaning-making resources; then, we interpret those resources as implying a set of cognitive units built up from bodily experiences; finally, we relate these cognitive units to the key features of a disciplinary treatment of the same topic. In doing so, we not only uncover a detailed story of how the students utilize their bodies in meaning-making and mechanistic reasoning, but we also offer the interested physics education researcher or teacher with a lens through which to value students' informal conversations such that they might engage with students in optimally responsive ways.

\section{THEORY AND METHODOLOGY}

In the section that follows, we give an overview of the theoretical perspectives of social semiotics and embodied cognition and discuss how they inform our case study. We then review some of the relevant PER literature on students' use of their bodies in learning and outline our paper's theoretical contribution to the PER literature base in this area. The review in this section is comprised of three parts, organized around the ways in which the body plays a crucial role in (i) how we communicate, (ii) how we think, and ultimately (iii) how we learn physics.

\section{A. The body and communicating: Multimodality, social semiotics, and conversation analysis}

Though language in written and spoken forms has historically monopolized the attention of those researchers and philosophers concerned with communication, a growing number of scholars in education (both generally and within PER) are beginning to attend to an expanded picture of communication $[5,6,12,20,21,25,26]$. These researchers are doing so by considering the multiplicity of ways by which individuals communicate beyond written and spoken language. Their studies are often referred to under the umbrella term multimodality $[18,19]$. For the purposes of our discussion, multimodality can be thought of as the notion that humans communicate in a variety of ways [19], i.e., not only with written and spoken language but also with gestures, gaze, manipulation of objects, static and dynamic images, haptic touch, ${ }^{1}$ body posture, etc. While multimodality is a perspective applied across many disciplines and to a variety of research topics, one school of

\footnotetext{
${ }^{1}$ By haptic touch, we refer to interpersonal contact which might act to push or pull an individual (i.e., human-human contact that includes a force, rather than, for example, the feeling of a surface's texture). See the end of Sec. II A.
} 
multimodal thought that has been meaningfully adapted into the domain of PER is that of social semiotics [5,27].

Social semiotics is the study of how social groups of people-from the scale of paired conversations up to the scale of societal contexts-develop and reproduce "specialized systems of meaning making," as realized through semiotic resources (meaning-making resources) [5] (p. 95). Within PER, studies utilizing social semiotics tend to take as a starting point the meaning potential of semiotic resources (often referred to as representations) used in the discipline of physics. An important area of interest for such researchers is the ways in which students develop "fluency" in the use of disciplinary semiotic resources and gain the ability to strategically select and coordinate resources by recognizing a set of disciplinary-relevant aspects (DRAs) ${ }^{2}$ relating to the task at hand [1,2,5,20,28,29].

To be clear, disciplinary semiotic resources are those meaning-making resources that the participants of a discipline use to make meaning within the discipline. In physics, these are most commonly mathematical expressions, scientific (spoken and written) language, graphs, and diagrams (e.g., free body diagrams, Feynman diagrams, ray diagrams, etc.). However, these also include - though less commonly so-certain gestures (see, for example, Ref. [30]). Nondisciplinary semiotic resources include those meaning-making resources that are not typically used in disciplinary discourse such as language that does not use scientific vocabulary, many gestures and, as in our case, haptic touch and full body enactment, such as dance. However, certain semiotic resources, including mathematics and gesture, for example, can be used in both disciplinary, as well as nondisciplinary ways. Thus, it is often necessary to interpret the disciplinaryness of a particular semiotic resource in a given context.

Studies using the social semiotics framework have found that semiotic resources which stand fast-or are persistent (e.g., graphs, diagrams, sketches) - play a central role in meaning making by serving as a hub around which other nonpersistent resources (i.e., talk and gesture) can be coordinated [21,31].

For the purposes of this paper, we depart from the typical implementations of social semiotics in PER by examining how students employ nondisciplinary resources while addressing DRAs of physics phenomena. To do so, we utilize and incorporate the analytic techniques from another school of multimodal thought, conversation analysis. Where social semiotics tends to take as its analytical starting point the resources of the discipline (though not exclusively so, e.g., Ref. [21]), conversation analysis tends to start analytically with the resources used by individuals as they engage in conversation.

\footnotetext{
${ }^{2}$ Disciplinary-relevant aspects are "those aspects of physics concepts that have particular relevance for carrying out a specific task" [29].
}

Conversation analysis (CA) involves the microlevel (moment-to-moment) examination of video-recorded conversations in order to determine how individuals build up actions and interactions in sets of mutually elaborating semiotic resources [19,32]. For example, Goodwin [33,34] used CA to examine how archeologists use gestures closely linked to their setting — which he calls environmentally coupled (or symbiotic) gestures-alongside talk to communicate within a dig site. In CA, systems of semiotic resources like gesture, gaze, and body positioning are considered in concert with the spoken and written words which occur simultaneously or in sequence. Multimodal utterances - those "chunks" of externalized communication which might include any range of semiotic resourcesshould be analyzed not only as expressions made by communicating individuals, but also as social acts that function to produce meaning with other sets of individuals. It is precisely this notion of building up action from multimodal semiotic resources, along with the methodological practices of close analysis and transcription of video footage, that we find useful for this case study.

As this paper deals with an interpersonal dance, we pay particular attention to the semiotic resource system of haptic touch. Literature on haptic touch, or simply haptics, can be found predominantly in two areas of research. The first is human-computer interface research, where the tools used to interact with computers have begun to incorporate resistive feedback or other sensorimotor stimuli [35]. The second is cognitive psychology research [36]. Within social semiotics, (haptic-)touch has received minimal attention, with much of the discussion centering on whether touch should qualify as a semiotic resource system in its own right—specifically, whether touch meets three necessary criteria ("metafunctions") for constituting a communicational mode in the same way that talk or gesture do [19,37-39]. For the purposes of this paper, we accept haptic-touch as a semiotic resource system insofar as we see it being used by students as they make meaning with each another.

\section{B. The body and thinking: Embodied cognition, conceptual metaphor, and embodied imagery}

The body has been viewed by many scholars as an integral and noteworthy counterpart to the mind since the 1980s, specifically in the branch of cognitive science termed embodied cognition [40-42]. Originally arising as a response to the isolationist versions of cognitive science that viewed the mind as a discrete information processor, embodied cognition is characterized by a focus on how personal bodily experiences, which are often common across individuals due to the similarity of our human bodies, serve to structure cognition and language. One of the more influential traditions of embodied cognition research, Lakoff and Johnson's [43] conceptual metaphor, centers around how humans form basic units 
of intuition called image schemas and recruit these schemas metaphorically during cognition and communication. From the perspective of embodied cognition or conceptual metaphor, then, image schemas are seen as the (prelinguistic) building blocks from which cognition is built up and that we acquire through repeated sensorimotor experiences.

Thus far, the perspectives of embodied cognition and conceptual metaphor have been fruitfully applied to science education research, particularly in studies that focus on students' use of analogy and metaphor in their spoken and written language [41,44-47]. PER has also seen the emergence of theories similar to conceptual metaphor in theoretical contributions such as the "knowledge in pieces" model of cognition, which takes phenomenological primitives ( $p$-prims) as the fundamental building blocks of thinking $[48,49]$.

However, while these irreducible, infinitesimal cognitive units of image schemas and $p$-prims are both useful constructs for discussing how the experiences of the body get into our thoughts and language, here we take a perspective that accounts for a larger grain size of cognitive unit. As we discuss in Sec. III C, a main impetus for this case study was to meaningfully analyze the semiotic function of the enacted dance carried out by our pair of students. We posit that an atomization of this act into irreducible image schema or $p$-prims would categorically miss one of the main affordances of the dance for the students: the dance evoked a single coherent mental image rather than an impromptu cobbling together of basic cognitive units. As seen in our analysis (Sec. IV), the dance appears to have functioned as a prefabricated, mutually understood act for the students.

Therefore, we choose to interpret our students' cognition-during the dance and otherwise-in terms of larger "chunks" of mental imagery [50,51]. We refer to these "meso-scale" cognitive units-which we emphasize are neither the "microscopic," irreducible building blocks nor "macroscopic" conceptions-as embodied imagery. By embodied imagery we mean to denote the source domain of the students' metaphoric language which is grounded [52] in embodied experiences with the material world. We see ourselves aligning with Reiner and Gilbert [51] in the view that "students construct meaning on the basis of mental structures of embodied imagination of a figurative, dynamic, nonpropositional character" (p. 502). To a degree, our perspective also resembles an aspect of another constructivist cognitive model within PER, namely, the "resource framework" $[8,53,54]$. Within the resource

\footnotetext{
${ }^{3}$ The "resources" of this cognitive framework should not be conflated with the "semiotic resources" from the social semiotic framework discussed in Sec. II A. While we use a cognitive model which does bear some resemblance to the framework with the former use of the term, our analysis in this paper makes use of the term 'resources' in accordance with the latter.
}

framework, an individual's long-term memory is seen as built up from both smaller "reasoning primitives" (akin to image schemas and/or $p$-prims) and also larger units called "facets" (i.e., reasoning primitives which have been mapped or applied to phenomena or objects in the concrete world). Though the relative size of facets as compared to primitives is not expressly discussed in the literature, we see a resemblance between the resource framework's facets and our embodied imagery in that they both contain a grounding in concrete experiences that appear to be called upon as a larger chunks of cognition (as opposed to irreducible cognitive units). Furthermore, for the kind of interactive learning scenario that constitutes our case study, greater value for physics instruction arguably comes when the analysis provides insight into how the imagery at this larger grain size can be mapped onto the DRAs of physics content rather than how the imagery might be traced to cognition's smallest building blocks (see Sec. III C). Still, by highlighting both the embodied nature of these cognitive structures and the metaphorical nature by which they come to be used in the students' multimodal interaction, we suggest that an analysis which is aligned most closely to the framing of the embodied cognition or conceptual metaphor perspective offers something new and worthwhile to the PER community. ${ }^{4}$ We use our methodology to interpret students' displayed actions (i.e., the uttered semiotic resources) in terms of the embodied imagery these actions imply. The embodied imagery can then, in turn, be seen as relating to (or not relating to) a set of DRAs for the task at hand.

\section{The body and learning physics: Existing PER work and our synthesis of perspectives}

The reality that learning is not only cognitive, but can also involve the body of the learner, has long captured the attention of philosophers, educators, and education researchers $[55,56]$. In the domain of physics education, interest in embodied learning has likely stemmed from the fact that much of physics' subject matter deals with the actions and interactions of objects at the scale of the human body [57]. Thus, involving students' bodies as active instruments and sensors can be a natural and intuitive approach for the interested physics educator. For example, students can feel forces (pressure) as they sit on carts and push each other around [58] or they can push objects along surfaces with varying coefficients of friction to "feel" the resistances those surfaces provide [59]. Even beyond phenomena at the human scale, there are educational advantages to be found in encouraging students to act as

\footnotetext{
${ }^{4} \mathrm{~A}$ similar analysis to the one carried out in this paper could perhaps be carried out with a commitment to a $p$-prims or resources approach. Still, we do not expect the insight generated from such an approach to be equivalent to what we present in this paper.
} 
metaphorical role players in processes physically much smaller [60] or much larger than themselves [61]. Such embodied learning allows students to relate their bodily intuitions to objects in otherwise physically nonintuitive domains.

Nonetheless, much of the existing PER work on bodily engagement in physics learning has not gone much beyond tracking the design and implementation of explicit instructional activities wherein students' bodies are included at the request of teachers. Here, the topic of the body as a tool for learning is often mentioned under the label of kinesthetic learning or kinesthetic learning activities (KLAs). Begel et al. define a KLA as an "activity which physically engages students in the learning process" [62] (p. 1). By this definition, KLAs include activities such as laboratory work or demos where students might interact with physical apparatus (e.g., Ref. [63]) but also those activities where students might use their bodies as sensors for physical interactions (e.g., Refs. [24,64-69]). Perhaps unsurprisingly, KLAs are relatively common in the physics literature as a way of leveraging students' bodily experience to make sense of physics phenomena [70,71]. KLAs have been shown as potentially effective means for engaging students [72] and improving learning outcomes in particular settings [62].

While the label of KLAs seems to apply to a broad range of activities which involve the body, finer distinctions and reformulations have been made to distinguish certain activities involving the body from others. Scherr et al. [22] introduce the concept of embodied learning activities (ELAs) as a subset of KLAs. In ELAs, a teacher incorporates students' bodies, or parts of their bodies, as metaphorical substitutes for physical entities in a role playing of physical phenomena (e.g., Refs. [60,61,73-75]). This is in contrast to the more generic KLAs, where a teacher incorporates students' bodies as sensors and nonmetaphorical participants in phenomena. For example, in the prototypical example of an ELA, Energy Theater, by Scherr et al. [22], students represent physical manifestations of energy, moving between designated locations in a room to enact transformations of energy such as in chemical bonding or in the heating of a lightbulb. Alternatively, a KLA on the same topic might involve the students using their hands to feel endothermic reactions or touch the surface of a light bulb in a circuit [76]. By involving the students' bodies as representations of physical entities, ELAs can help students draw and explore metaphorical parallels between characteristics of their bodies and the entities they represent in phenomena. In our study, however, the students appear to use their bodies in a manner which seems to involve elements of both KLAs and ELAs. Therefore, we see the students' interactions in our case study as an example of embodied learning in physics which defies categorizations such as Scherr et al.'s [22]. As we show below, our data appeal to the need for a closer examination of the moment-by-moment involvement of students' bodies as they learn physics.

Other recent education research has examined embodiment in technology-based learning environments, such as with technologies that incorporate augmented or mixed reality [77-80] or haptic feedback [81]. Lindgren et al. [82] find that involving students' bodies in fullbody interactive simulation-as compared to students using mouse-and-keyboard interfaces - can lead to an increase in students' conceptual understanding and might favorably shift the affect and motivation of these students as they learn physics. Similarly, Johnson-Glenberg et al. [79] suggest a way to taxonomize the degrees of embodiment in educational technology, including the criteria of (i) "motoric engagement," (ii) "gestural congruency (i.e., how well mapped the evoked gesture is to the content to be learned)," and (iii) "perception of immersion" (p. 89). After comparing students using lowembodied technology to students using high-embodied technology, the authors posit that instructional design that is embodied to the highest degree-by way of maximizing these three criteria - and which takes advantage of collaboration, leads to students learning more content and remembering that content longer. Such research shows promise for revealing how students' technologically enabled embodiment benefits their learning of science. We see our work in this paper as also contributing to this conversation, particularly in the context of physics, by providing a moment-tomoment account of students' embodied engagement in a technology-rich learning environment.

Having discussed the various theoretical underpinnings to our methodological approach, we now elaborate on how we bring together these perspectives into a coherent system for analyzing students' interactions (shown in Fig. 1). We start analyzing students' conversation by breaking down

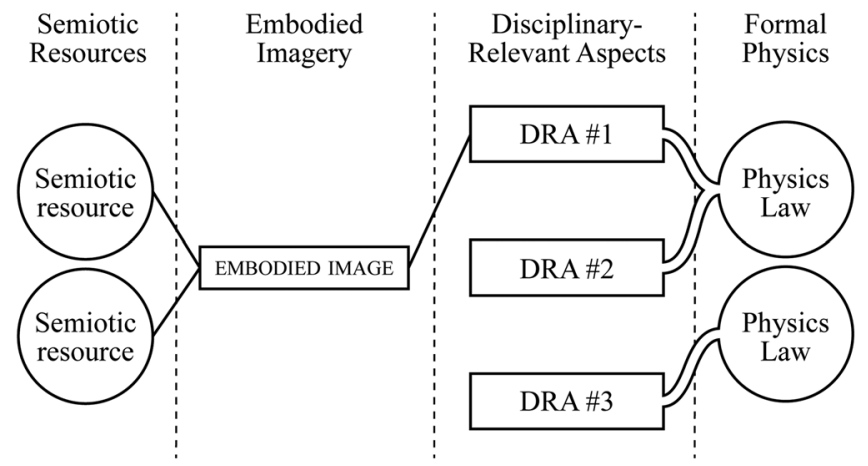

FIG. 1. A diagram of the analytic approach used in this paper. Our approach entails that we first observe the semiotic resources used by students (leftmost column) and interpret these resources in terms of the embodied imagery which they seem to imply (center-left column). We then compare this embodied imagery to DRAs (center-right column). The DRAs are seen to be facets of the disciplinary physics laws (rightmost column) used in a formal treatment of the task at hand. 
their multimodal utterances (moment-to-moment) into constituent semiotic resources (leftmost column, Fig. 1, as aligned with the practices of CA). We then interpret the embodied imagery associated with each of these utterances based on both the involvement of embodied semiotic resources and also the metaphorical structure of the resources in relation to one another (middle left column, Fig. 1, as aligned with the perspective of embodied cognition). Since we are interested in the degree to which the students' nondisciplinary communication relates to DRAs, we then examine how the interpreted embodied imagery could be seen as relating to a set of DRAs identified from a disciplinary treatment of the task at hand (middle right column, Fig. 1, as aligned with the perspective of social semiotics). The DRAs identified in our analysis are seen as facets of formal physics laws (rightmost column, Fig. 1), such as Newton's third law, and constitute the relatively fixed semiotic patterns that make up the discipline of physics [83]. In this way, we compare the students' dynamic, negotiated, and nondisciplinary meaning making on the one hand (left half of Fig. 1) with the more fixed system of disciplinary physics on the other (right half of Fig. 1).

To illustrate our analytic approach further, we use an example from our study. In the two-person, Titanic-esque dance, we observe two students holding hands and leaning outward from each other (ostensibly, imagining spinning around). In performing this action, the students are employing the semiotic resources of body position and haptic touch. Thus, if one places the students' interaction in a diagram like Fig. 1, these two semiotic resources occupy the leftmost column (Fig. 2). Next, while we temporarily defer what we acknowledge is a crucial explanation (see Sec. IV) for the sake of illustrating our framework, we posit that these two semiotic resources combine to invoke an embodied image of ROTATING IN A PARTNER DANCE (middle-left column, Fig. 2). As will be detailed below, the two students are addressing a question within the context of binary star dynamics, a question for which the discipline would regard it as relevant that (i) the system involves two bodies that are (ii) reciprocally interacting with one another, (iii) determining each other's motion by (iv) pulling inward toward each other. These four (numbered) aspects are what we identify as the DRAs for the question at hand (middle-right column, Fig. 2). Each of these DRAs can be seen as a contextualization of three formal concepts: namely, Newton's third law, Newton's second law, and Newton's law of gravitation (rightmost column, Fig. 2). The ROTATING IN A PARTNER DANCE image is a multifaceted one and likely the largest chunk of the mental elements which we identify under the category of "embodied imagery." Even in the initial posing of the dance when the two students simply hold hands and lean outward from each other, it is apparent that the ROTATING IN A PARTNER DANCE image necessarily requires two people pulling on each other symmetrically to spin around.

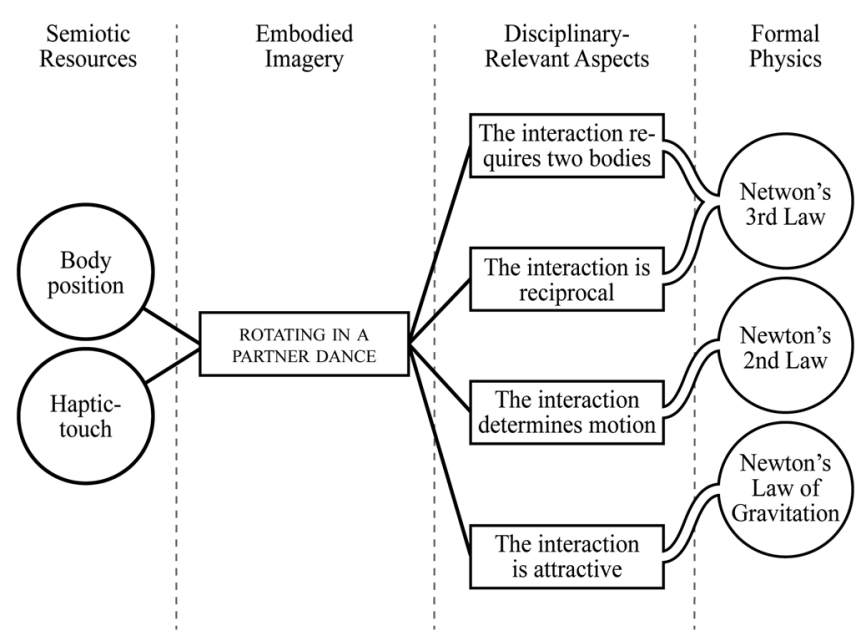

FIG. 2. A diagrammatic representation of our analysis applied to the titular example of embodiment in this paper: the dance. We identify the semiotic resources of body position and haptic touch (left column) as invoking the embodied image of ROTATING IN A PARTNER DANCE (middle-left column). This image can be seen as relating to all four DRAs (middle right column) for our given question (Sec. IVA), which in turn are aspects of three formal physics laws (right column).

Thus, simply by virtue of its material characteristics as a physical act of the two students, the dance can be seen as relating to all four DRAs for the question at hand (Fig. 2). Eventually, as shown in the analysis (Sec. IV), the students elaborate on the ROTATING IN A PARTNER DANCE image via other semiotic resources in order to highlight the relevance of specific aspects which we see as relating to particular DRAs.

\section{THE STUDY}

\section{A. Experiencing orbital motion in PhET's My Solar System}

As discussed in Ref. [12], the topic of orbital motion receives only nominal attention in most upper-secondary physics programs, where students may be expected to simply know Kepler's laws by name and formulation, for example. This surface level treatment of orbital motion may be due, in part, to the fact that celestial phenomena take place on spatial and temporal scales far removed from those of humans in everyday contexts. Additionally, a rigorous mathematical treatment, which might provide another avenue for students to engage with orbital motion other than their intuitions, is likely to be beyond the skill level of upper-secondary (and even introductory university) physics students. Dynamic computer visualizations-which can display how the positions of celestial bodies evolve with respect to time-have offered some ways for teachers to make orbital motion more visually accessible to students, but the students merely watching such visualizations are likely to remain relatively passive. 


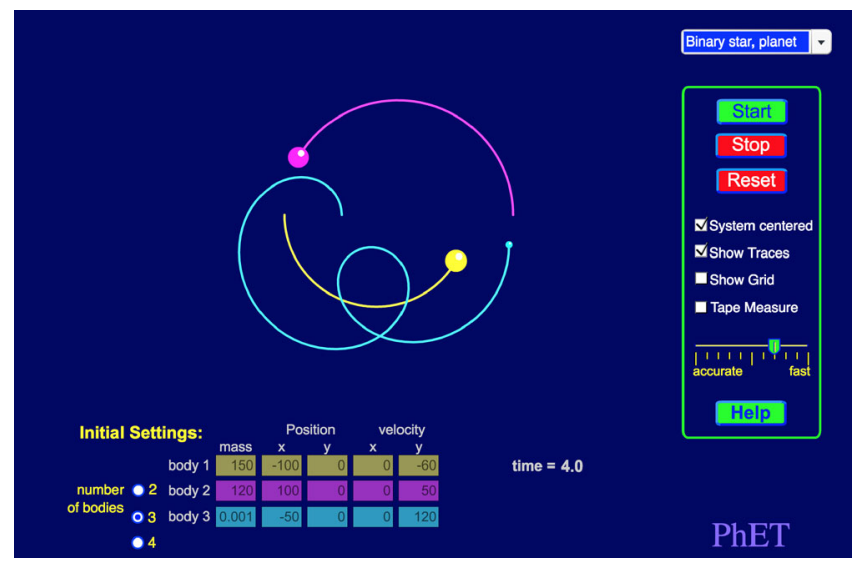

FIG. 3. A screenshot of the PhET simulation, My Solar System, on the "Binary star, planet" preset, showing the simulation a short while after hitting the Start button (the green rectangle, in the upper-right). The presets drop-down menu can be seen above the start button (highlighted in blue from this particular preset being selected). Along the bottom of the interface, users can enter values with a keyboard to precisely set the mass, $x$ and $y$ positions, and $x$ and $y$ velocities of the bodies in the system.

Alternatively, user-friendly simulation software provides environments in which the topic of orbital motion can be approached with an emphasis on student inquiry. Software such as the My Solar System simulation from PhET [15] and the open-ended digital environment of Algodoo, especially when combined with collaborative interfaces such as an interactive whiteboard (IWB) [84], provide small groups of students with the opportunity to explore orbital motion and Kepler's Laws for themselves [12,84-86]. Students who are encouraged to explore orbital motion with these digital learning environments have been shown to spontaneously engage with the topic in ways which mirror sciencelike exploration [12]. ${ }^{5}$ In this spirit, Gregorcic and Haglund [87] use the interpretive lens of conceptual blending to theorize how the combination of simulation software and IWB allows students to compress celestial phenomena to the human spatial and temporal scales, thereby making it possible for students to explore and experience orbital phenomena in a "hands-on" fashion.

In this study, we look at a pair of students using the PhET simulation, My Solar System, on an IWB. My Solar System is a two-dimensional simulation software which allows users to create circular bodies of varying masses, give them initial velocities, and observe how the created systems behave (Fig. 3). In contrast to Algodoo (the software studied in Ref. [12]), which due to its open-ended nature, allows for a wider variety of user-created objects and dynamic touchscreen inputs-the My Solar System software utilizes

\footnotetext{
${ }^{5}$ For a discussion of how to incorporate instructional technology into an educational treatment of orbital motion at the uppersecondary or introductory university level, see Ref. [12] and references therein.
}

prefabricated orbital scenarios, termed presets. In $M y$ Solar System, students will typically start their exploration with one of these presets and then edit the features of the preset to see how the masses and starting velocities of the bodies in the simulation affect the motion. The My Solar System simulation software was originally selected as an object of study (in Rådahl's master's thesis project [85], as discussed below), in part, to examine how its preset-based structure differed from the open-ended structure of Algodoo. In our study, we ultimately attend less directly to the students' use of the My Solar System software itself. Instead, we examine the students' interaction with each other, as set against the technologically rich backdrop of the PhET simulation on the IWB. What results is an interpretation of the students' interpersonal exchange, a conversation that is prompted by and consistently leverages the dynamic digital learning environment of My Solar System.

\section{B. Methods of data collection}

Our data were initially collected as part of a master's thesis project in PER [85], which investigated when and how responsive teaching techniques [11] might be effectively applied during open-ended learning activities involving small groups of students in digitally rich environments. Six students were recruited from a class of Swedish seniorlevel high schoolers, all of whom were enrolled in a threeyear natural science program. ${ }^{6}$ This particular class of students was chosen on the basis that Rådahl had spent eight weeks interacting with them during the previous year as part of his preservice teacher education program practicum requirements. It was believed that a positive rapport had been developed during those eight weeks such that these students would be more likely to participate in the study when asked. The recruitment process involved making an announcement at the high school, where the project plan was described and the students were invited to volunteer for the study along with a friend of their choice from class.

The students volunteered in pairs and each pair met Rådahl at Uppsala University for a session lasting approximately two hours. The sessions, which took place in a small, otherwise-vacant room equipped with an IWB, involved three parts: (i) a brief introduction to the study, (ii) an open-ended activity around orbital motion where students used both the My Solar System software and also Algodoo (one application at a time), and (iii) a brief exit interview. As the students were not experienced users of either My Solar System or Algodoo, they were given a short introduction to both digital environments by the researcher and then prompted with the instruction "to explore how small bodies behave around larger ones and to learn about

\footnotetext{
${ }^{6}$ The upper-secondary school level in Sweden (gymnasieskola, roughly comparable to U.S. grade $11-12+$ ) requires a topical focus, such as natural science or social science.
} 
orbital motion" [85]. The students were explicitly encouraged to explore anything which interested them related to that topic and to share their thoughts out loud as they did so [88]. The researcher remained present throughout the activity, providing technical support with the software and the IWB, offering advice on how best to use the software when the students were stuck, encouraging them to go further with interesting discussions, and occasionally requesting clarification from the students as to why they chose to do one thing or another.

The sessions were video recorded via a digital camera placed across the room as well as via screen-capture recordings from the IWB. Despite the researcher and the pair of students being the only people present in the room, the video sources were also supplemented, as a back-up measure, with an audio recording from a phone placed face down on a table near the students.

\section{Selection and presentation of data}

For our case study, we bring into focus a 2.5-min section of video data involving one of the pairs of students. Our selected video clip contains the interaction of two students that we refer to as Adam and Beth. The chosen 2.5-min section of video data occurred approximately an hour and a half into the overall session, while Adam and Beth were exploring orbits with My Solar System. The students had already spent approximately $45 \mathrm{~min}$ exploring orbits in Algodoo as well as approximately $30 \mathrm{~min}$ with the My Solar System simulation. This clip of video data was selected for our study because it includes a unique interaction between the pair of students, the likes of which we had not seen reported in a PER context. Unprompted to do so by the researcher in the room, Adam and Beth can be observed spontaneously engaging in an enacted analogy as a means of communicating and mechanistically reasoning about aspects of binary star dynamics. The enacted analogy was identified as a rich example of embodiment in physics which warranted analytic attention of a new kind.

In our presentation of the data, we use sections of transcript- translated by the research team from the students' native Swedish ${ }^{7}$ - as well as illustrations drawn from frames of the video data. Each line of the transcript is numbered and labeled with the student's pseudonym who spoke or acted out the content of the line. The transcript comprises the students' speech (written in plain or underlined text) and/or nonverbal actions (written in [bracketed, italicized] text). In order to convey the coincidence of some of the verbal and nonverbal communicative actions, we

\footnotetext{
${ }^{7}$ The original analysis of this exchange was done within Swedish and-especially when analytic claims were made from specific English phrases or words - the points made throughout the English analysis were checked to be consistent with the Swedish version as well. For a fully detailed transcript of Adam and Beth's interaction (with the Swedish and English side by side), see the Supplemental Material [89].
}

underline the portions of the lines which coincided with a particular action and then describe the coincident action in the brackets immediately following the underlined text. For example, the line "Mhm, yeah. I agree. [nods her head]" would be used to refer to an instance where the speaker nodded her head while saying "I agree," but did not nod during "Mhm, yeah." Alternatively, in order to convey speech and actions that occurred consecutively, we omit an underline in the transcript. Thus, "Mhm, yeah. I agree. [gives a thumbs-up to Adam]" would be used to refer to an instance where the speaker first spoke the words "Mhm, yeah. I agree" and then gave a thumbs-up to Adam after she finished speaking.

With attention to the significant instances during communication that were embodied or enacted, we also include illustrations of the gestural actions. These illustrations were digitally drawn from specific frames of the video data and include speech bubbles of the proximate talk in a style similar to a comic book. Arrows are superimposed on the illustrations to highlight the movements of the students' bodies. These illustrations are included to convey the multimodal nature of the students' interaction in a manner that goes beyond the descriptive power of a written transcript alone and which we believe also provides a clearer representation of the video data than the still frames of video would have themselves (as seen in Refs. [42,87,90]). Taken together, the written transcripts and illustrations constitute what is typically referred to in the literature as a multimodal transcription $[91,92]$. As both the transcripts and illustrations are instances of our purposeful selection [93] and re-representation of the audio and video data, they should not be viewed as equivalent to the raw data of the video and audio files themselves [94].

\section{DATA AND ANALYSIS}

We study the 2.5-min portion of Adam and Beth's videorecorded conversation which precedes, comprises, and follows the enacted analogy of the dance. By way of a preamble to our analysis, we first examine the physics topic that the two students discussed from a disciplinary perspective, and in doing so, further clarify the methodological lens through which we choose to analyze Adam and Beth's interaction. We then present and analyze the video data in three segments in order to interpret how the two students incorporated their bodies into their communication and mechanistic reasoning about orbital motion.

\section{A. The topic: The periods of binary stars}

For the duration of the selected video clip, Adam and Beth are exploring the reason why binary stars never begin to orbit "out of phase" with one another-i.e., both stars complete their orbit in the same amount of time. Specifically, the students are discussing the following question, which we refer to throughout the remainder of the text as the orbital 
period (OP) question: Why are the orbital periods of the two binary stars always the same as each other? This question is first posed by Beth and it serves as both of the students' focus for the 2.5-min clip that we analyze below. However, before we analyze the ways in which Adam and Beth came to answer the OP question, we first examine the critical features of a disciplinary answer in order to establish a disciplinary reference point against which we can compare Adam and Beth's conversation. Ultimately, we interpret the extent to which each informal utterance made by the students seems to relate (via embodied imagery) to the formal concepts which would be used by physicists in answering the OP question.

Though the OP question might not be considered a common discussion topic for many physics or astronomy classes, in what follows, we model how a physicist might construct an answer if the OP question happened to surface. ${ }^{8}$ First, we assert that binary stars make up a two-body system wherein both bodies interact via centrally directed, reciprocal forces. These forces are described by the Newtonian law of universal gravitation, being attractive and falling off with inverse square of the distance between the objects' centers (valid for spherically symmetric objects). In such a system, Newton's laws of motion can be used to find that both bodies move on elliptical orbits with a common focus at the center of mass of the system.

One can explain the equally long orbital periods by solving the two-body problem analytically (which we do not do here for the sake of brevity). Since each body is accelerated only by the centrally directed force exerted by the other body, and since the center of mass of the system is always located on a straight line drawn between the two bodies, each body must always be located directly across the center of mass from the other body (though at a changing distance for noncircular orbits). Thus, as one body passes through a single revolution on its elliptical orbit around the center of mass of the system, the other body will necessarily remain opposite it at every point of the orbit, thereby completing a single revolution simultaneously with the first.

However, the OP question, as it was posed by Beth, can be addressed without necessarily being familiar with the full analytical solution to the two-body problem, including the exact shapes of the bodies' orbits. Some implications can be drawn directly from fundamental principles that we use to deal with the two-body problem. For example, the accelerations of the two bodies are related by Newton's 2nd law to the forces the bodies exert on each other. The accelerations of respective bodies are thus parallel to the net

\footnotetext{
${ }^{8}$ There are, certainly, many different ways that a physicist might choose to answer the OP question, ranging from entirely mathematical to predominantly conceptual. For the purposes of our analysis, we present a more basic conceptual answer, as the features of such an answer can be more readily compared to the informal interaction of the two students.
}

force experienced by each body (in this case the same as the force exerted by the other body), which are themselves related by Newton's 3rd law (equal in size an opposite in direction). Following from Newton's laws, the temporal evolution of the direction and size of respective accelerations will also be similar for both bodies. The respective accelerations therefore always face in exactly opposite directions-and in the case of differing masses, have different sizes-yet maintain a constant ratio of sizes and change simultaneously in direction and absolute size (due to changing distance between the bodies as per the law of universal gravitation). In this way, we can see how a periodic change in one body's acceleration will necessarily mean the same period of change in acceleration for the other body, both in terms of direction, as well as size. We now apply the above reasoning to the case at hand. If one of the two bodies were to have a different orbital period than the other, this would also entail a different temporal evolution of its acceleration. In the case of elliptical orbits, where each point of the orbit has a unique direction of acceleration, this is particularly clear. The proposal of different orbital periods for the two bodies thus violates Newton's laws of motion. As we will see later in the paper, the students' reasoning, while not formulated in physics disciplinary language, is remarkably similar to the one presented here.

Below, we propose a selection of DRAs $[20,29]$ that will allow us to compare some of the aspects of a disciplinary analysis of the OP question with Adam and Beth's reasoning. Fundamentally, a disciplinary conceptual treatment begins with an appreciation that the stars' motion can be accounted for by Newtonian mechanics. Thus, a qualitative answer to the OP question in the given context might be seen as incorporating Newton's third law, Newton's second law, and Newton's law of gravitation by way of four DRAs:

- $\mathrm{DRA}_{1}$ : the orbital phenomenon of the binary system involves the interaction of two bodies,

- $\mathrm{DRA}_{2}$ : the two bodies are interacting reciprocally with one another,

- $\mathrm{DRA}_{3}$ : the interaction of the bodies with one another is what determines their motion,

- $\mathrm{DRA}_{4}$ : the interaction is attractive in nature.

These four DRAs can be seen as specific facets of the three Newton's laws mentioned above, phrased in a qualitative manner which accompanies the OP question. As summarized in right half of Fig. 2, DRA 1 and $\mathrm{DRA}_{2}$ can be seen as facets of Newton's third law, $\mathrm{DRA}_{3}$ as a facet of Newton's second law, and DRA 4 as a facet of Newton's law of gravitation. These four DRAs outlined above constitute a conceptual treatment of the OP question as aligned with the discipline of physics.

Now, as we analyze Adam and Beth's interaction in the sections that follow, we examine the more informal semiotic resources the pair uses while reasoning about the OP question in relation to these four DRAs. Specifically, 


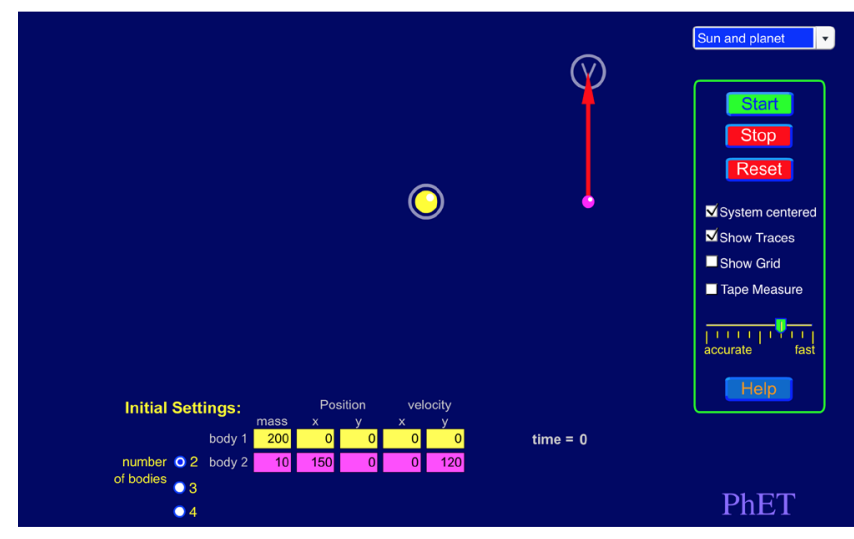

FIG. 4. A screenshot of the My Solar System simulation showing the "Sun and planet" preset.

we interpret the semiotic resources used by Adam and Beth (such as talk, gesture, haptic touch, and body position) as implying embodied imagery and then compare this embodied imagery to the DRAs identified above. In this way, we make visible the ways in which the students' informal communication appears to match the character of more formal physics.

\section{B. Segment 1: Before the dance}

The first segment of our data begins as Adam and Beth start to explore the motion of binary stars. In the time leading up to the first lines of the transcript, Adam and Beth select the "Binary star, planet" preset within $M y$ Solar System (Fig. 2), which involves two larger (starlike) bodies and one smaller (planetlike) body. The students allow the simulation to run for a few seconds, but upon seeing how complicated the motion of the three bodies is, Beth decides to construct a simpler binary star setup of her own by choosing the "Sun and planet" preset (Fig. 4) and then setting the masses of the two bodies equal to one another.

As the pair of students begin to explore this new binary star system on the IWB, Beth is surprised to see that both stars take the same amount of time to complete a single revolution in their respective orbits, especially while she changes the mass of one of the stars such that they are unequal again. Though it takes her many tries to explain her surprise in the right words, Beth eventually says to Adam, "but they are still the same [as each other]. The orbital period[s are] the same. They have different orbits but will still get the same orbital period." After the two students change the masses of the stars one last time Beth asks

1 Beth: Why does it happen like that? [watching the IWB]

2 Adam: Because it's for only two planets, so it's-[points index fingers upward, Fig. 5(a)] I mean, you must always have a counterforce toward where the other planet is.

3 Beth: Yeah. [looks at IWB]
4 Adam: And if it changes faster... well then, I mean, the count-then there won't be created any counterforce. [follows the small, circular shape of the more massive star's orbit with his index finger on the IWB, Fig. 5(b), left; then, looks back to Beth, Fig. 5(b), right]

We first want to flag the way that Beth originally formulates the OP question, as it becomes relevant for tracking the progress of the students' interaction. When Beth asks the question "why does it happen like that?" in line 1, we take it that she is inquiring into why the system of two stars behaves as it does. ${ }^{9}$ Though Beth specifically talks about the periods of each body in the time leading up to the OP question in line 1, she ends up using a phrasing that emphasizes the phenomenon as a whole. Given that our formal treatment of the OP question involves an appreciation of the reciprocity of interaction between two bodies, Beth's wording of the OP question suggests that she is considering the phenomenon in a manner which is "too holistic." Indeed, though we do not claim to know what Beth was thinking, if we examine the way she spoke about the orbiting stars in line 1 of the transcript, she does not clearly express an appreciation of any of the four concepts we highlight in the formal treatment above.

In his first attempt to answer Beth's question, perhaps in response to how Beth had inquired about to the behavior of the phenomenon as a whole in line 1, Adam chooses to emphasize that the binary system is made up of two distinct, interacting bodies. He centers his fingers symmetrically over his shoulders in a way which we take as referring to two discrete objects that are playing equivalent roles in a phenomenon. Together, his speech and gesture in the beginning of line 2 feature an embodied image of a SYMMETRIC PAIR. In comparing this part of his utterance to the DRAs for answering the OP question, this implied embodied image strongly resembles $\mathrm{DRA}_{1}$, that the interaction requires two bodies.

Adam goes on in line 2 to say, "you must always have a counterforce toward where the other planet is." Here, his use of the word counterforce (translated from the Swedish, motkraft) is of particular interest, not least because it seems to be an example of Adam attempting to incorporate more formal vocabulary while answering Beth. On the one hand, a "counterforce" grammatically counters something, namely, another force. Thus, Adam's use of the word implies a RECIPROCITY OF INTERACTION between two bodies. Such an embodied image could be worthwhile in the discussion of the OP question, as it relates to $\mathrm{DRA}_{2}$, that the two bodies interact reciprocally with one another. On the other hand, however - and despite our being able to see counterforce as

\footnotetext{
${ }^{9}$ Beth uses the third-person singular pronoun "det" (in English, 'it') as the subject of the question, which, due to the en and ett system for nouns in the Swedish language, excludes the possibility of her referring to a specific planet by itself.
} 

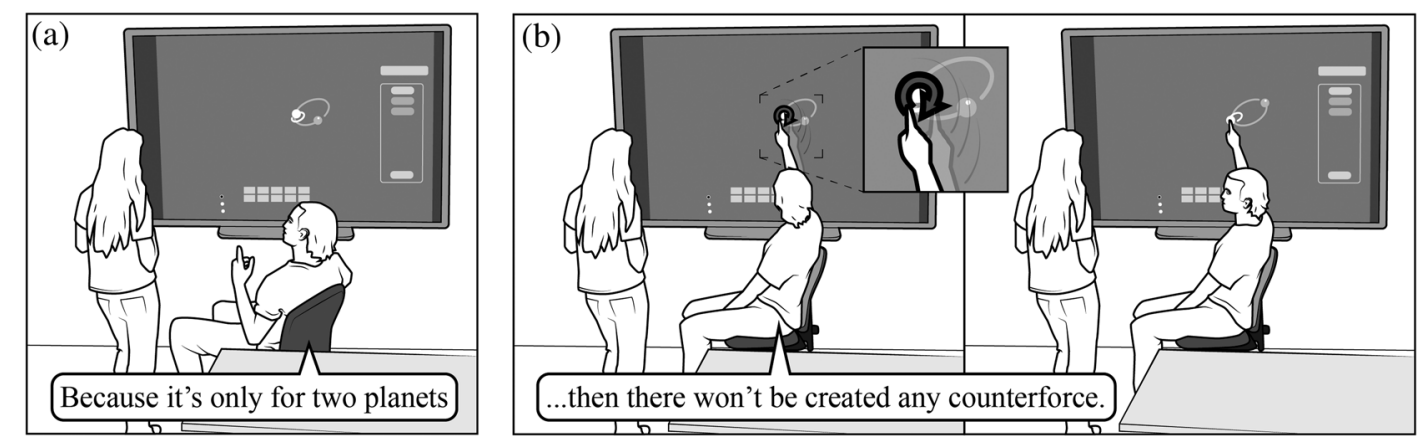

FIG. 5. Illustrations of Adam's multimodal utterances in (a) line 2-where we see him including an embodied image of a RECIPROCITY OF INTERACTION, and (b) line 4-where he can be seen involving an embodied image of FORCED AROUND.

an expression of a RECIPROCITY OF INTERACTION-it is not clear what Adam means with the word while communicating with Beth. Thus, Adam's use of counterforce is both a potential implication of a useful embodied image, and also a somewhat ambiguous term in the context of his conversation with Beth. In addition to using counterforce, Adam indicates a directionality to the interaction of the stars in his use of the word "toward." By stating that "you must always have a counterforce toward where the other planet is," Adam implies an embodied image of ATTRACTION, as is used in Newton's law of gravitation and is captured in $\mathrm{DRA}_{4}$, that the interaction is attractive in nature.

In line 4, Adam presents a counterfactual conditional statement, "and if it changes faster, [...] then there won't be created any counterforce." Adam uses this counterfactual in his arguments several times over the course of his answering the OP question. The counterfactual seems to be that, if star 1 were to orbit faster than star 2 in a binary system, this would result in a lack of a counterforce, which Adam appears to find important in some way for explaining the stars' motion. Here in line 4, Adam does not present his counterfactual in a clear manner and it is only with the context of the following section that we (as researchers) are able to understand what he means. Adam uses vague wording such as "if it changes" and "be created any counterforce" without explaining what is changing or what it means to create a counterforce, or how it relates to the other star's motion.

Still, as the words of the counterfactual scenario co-occur with a circular gesture at the IWB, we infer that Adam is semantically linking his notion of counterforce (however ambiguous the term remains) with the orbital (circular) motion of one of the stars. This multimodal utterance relates to and implies an embodied image of FORCED AROUND since it involves an object being moved around in orbit by some force. Thus, this embodied image can be seen as resembling $\mathrm{DRA}_{3}$, that the interaction determines motion.

We see at the end of line 4 that Adam turns his gaze back to Beth as if to check how well his explanation is working. However, unlike in line 2 where she encourages Adam to continue, after line 4, Beth silently gazes at the IWB, offering no confirmation to Adam that she has followed his reasoning. Indeed, from her reaction and from the ambiguity of his utterances, we suggest that Adam's attempt to explain his answer to her question has not convinced Beth thus far. Nonetheless, while his utterances do not work in the context of the conversation, we are still able to interpret Adam's utterances as involving each of the four critical aspects used in answering the OP question. In the next segment, Adam tries to answer Beth's OP question again, this time using the dance to better convey the same formal concepts he has already begun to involve in lines 2 and 4 .

\section{Segment 2: The dance}

When Beth does not respond to Adam's utterance in line 4, Adam chooses to involve his and Beth's bodies to act out his reasoning. It is at this time that we see the first instance of the dance, which the students eventually enact twice.

5 Adam: If you and I were to rotate around like this [extends both hands to Beth, Fig. 6(a), left]

6 Beth: Mhm. [grabs Adam's hands, Fig. 6(a), right]

7 Adam: Then I cannot start to rotate faster than you... [pulls on Beth's hands, then rolls in his chair to the side of Beth while trying to pull in the direction of his original position, Fig. 6(b)] even though you weigh less than me. [points to Beth, then puts hands down]

In lines 5 and 7, Adam involves Beth in a dance, which we see as a coordinated set of semiotic resources including haptic touch and body position. Importantly, however, despite being composed of distinguishable resources, the dance seems to elicit a single, coherent embodied image: ROTATING IN A PARTNER DANCE. Unlike the sets of semiotic resources used by Adam in lines 2 and 4, the set of semiotic resources in the dance are coordinated as a single multimodal ensemble and connote a unitary image of embodied action. It is important to note here, that, while it may be unsurprising to the reader that acting out a dance in this situation might invoke ROTATING IN A PARTNER DANCE for the two students, we emphasize that it should not be taken for granted that coordinated sets of semiotic resources produce coherent embodied imagery. For example, compare 

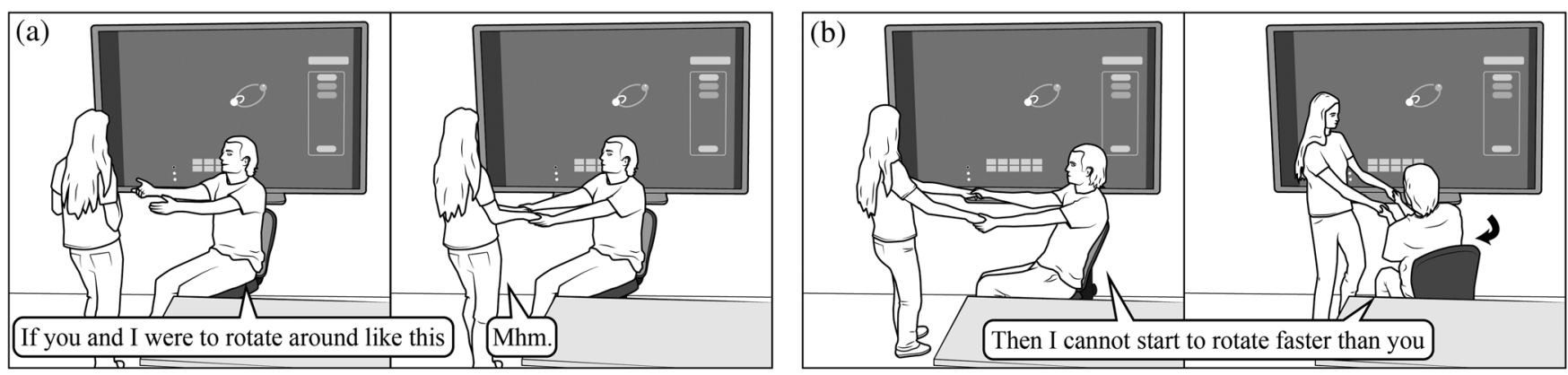

FIG. 6. (a) Adam offers his hands to Beth with an invitation to "rotate around" (line 5). (b) Adam then acts out an unrealistic overrotation in the dance context by scooting in his chair (line 7). This is the dance, which resembles the spinning that Jack and Rose do in Titanic and that we suggest implies an embodied imagery of THE EXPERIENCE OF DANCE.

the talk and gesture used by Adam in lines 2 and 4 with the haptic touch and body position of the dance in lines 5 and 7 (leaving aside talk and gesture in this case, for now). In the first instance, as we have argued, talk and gesture seem to coordinate in a manner that make implicit reference to embodied imagery. In the second instance, haptic-touch and body position of the dance coordinate in a manner that makes explicit reference to an embodied image. In both of these cases, Adam coordinates semiotic resources in an effort to make multimodal meaning, but only in the latter do we see a robust, unambiguous embodied image. With the dance, Adam communicates with Beth via the participatory semiotic resources of haptic touch and body position as part of a pattern of behavior, which seems to require no abstraction.

Now, in examining how ROTATING IN A PARTNER DANCE relates to our formal treatment of the OP question, we can see that this embodied imagery has the potential of relating to all four DRAs: the dance is an activity where two people $\left(\mathrm{DRA}_{1}\right)$ pull $\left(\mathrm{DRA}_{4}\right)$ on one another $\left(\mathrm{DRA}_{2}\right)$ as a means of rotating around $\left(\mathrm{DRA}_{3}\right)$. In this way, ROTATING IN A PARTNER DANCE has an explanatory potential for answering the OP question in a manner that goes beyond the embodied imagery employed across lines 2 and 4 (before the dance).

Furthermore, in line 7 we see Adam talk and gesture around the dance in order to highlight particular aspects for Beth. Since the dance involves the powerful, embodied imagery of ROTATING IN A PARTNER DANCE through the coordination of haptic touch and body position, Adam is able to leverage other semiotic resources, namely, talk and gesture. By doing so, he is able to comment on the dance as he answers the OP question. Line 7 shows him acting out the same counterfactual he introduced in line 4 by overrotating his body position in the dance with respect to Beth and saying, "then I cannot rotate faster than you" [Fig. 3(b)]. Here, it seems that Adam is relying on Beth's instincts about the dance—or more precisely her embodied intuitions about ROTATING IN A PARTNER DANCE-so that she will recognize that his improbable overrotation in the dance analogically relates to the impossible "decoupling" of the orbital periods in the binary star system. Adam also draws attention to how an overrotation is unrealistic despite the difference in his and Beth's masses. This is likely offered as an explanation for why Beth's changing of the stars' masses in My Solar System before the OP question did not result in the stars becoming "out of phase" with one another. When he uses the additional semiotic resources of talk and gesture around the dance-along with a variation of his body position in relation to Beth ${ }^{10}$ - in a representation of the counterfactual from line 4, Adam is foregrounding the features of the dance which relate to $\mathrm{DRA}_{3}$. This is an example of how, though the ROTATING IN A PARTNER DANCE image has the potential to relate to all the DRAs, specific attention can be drawn to DRA-specific features within the ROTATING IN A PARTNER DANCE image through the inclusion of other semiotic resources. As Adam finishes his thought, he pauses to let Beth reply.

8 Beth: Because they are holding each other... [turns to look at the IWB and brings hands together, interlocking her fingers, Fig. 7, left] in some way. [turns back to Adam and extends her hands toward him, Fig. 7, right]

In line 8 , we see Beth trying to explicate the analogical relationship between the binary star system and the dance. She gestures to suggest holding by bringing her hands together while looking at the IWB, then extends her hands while facing Adam in reference to the dance. She uses the pronoun "they" (de in Swedish) to indicate that she is referencing the stars, but combines this with a gesture that refers to the dance she just completed with Adam (Fig. 7, right). Especially when compared to Beth's utterance in line 1 , her utterance in line 8 seems to involve something of a HOLDING TOGETHER embodied image. When compared to the DRAs used in our formal treatment, we see that the HOLDING TOGETHER image shares a resemblance with $\mathrm{DRA}_{1}, \mathrm{DRA}_{2}$, and $\mathrm{DRA}_{4}$.

\footnotetext{
${ }^{10}$ Indeed, purposeful variation of semiotic resources seems to be a critical feature of Adam's more successful utterances. An attention to Adam and Beth's interaction from a variation theory $[6,29]$ perspective could offer some useful insights, but given the length of this manuscript already, we choose to leave it now as an open topic for future research.
} 


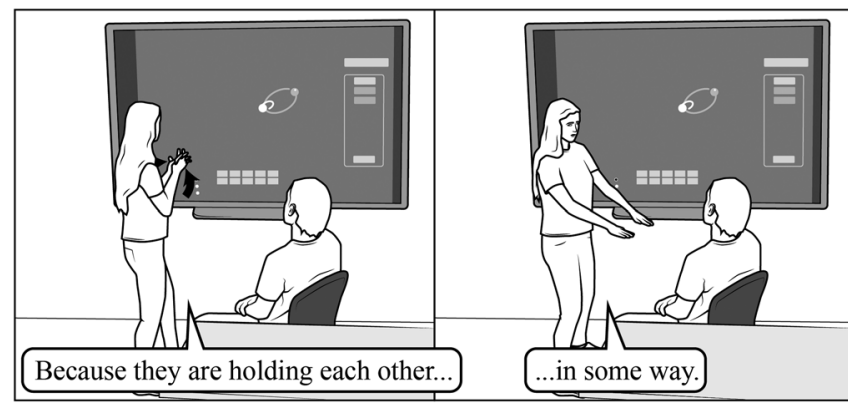

FIG. 7. Beth demonstrates her interpretation of the relationship between the dance and the orbiting stars with two gestures indicating an embodied image of HOLDING TOGETHER (line 8).

While the attractive nature of the interaction between the stars is invoked multiple times in Adam and Beth's interaction, it is, perhaps surprisingly, never elaborated on by the students in terms of gravity, the physical mechanism in the astronomical realm with which they were certainly familiar. We do note, however, that the activities preceding and following the excerpt presented here dealt with gravitational interactions quite explicitly, and both students expressed an appreciation of gravity as the mechanism of interaction between the involved celestial bodies. By saying that the stars are holding each other "in some way," Beth presents a ripe opportunity where the students might have linked their discussion with more formal terminology. Yet, as we see throughout the rest of our analysis of Adam and Beth's interaction, this gravity thread is never teased out explicitly. Nonetheless, by her utterance in line 8 , we can suggest that the dance has made Beth more aware of the two-bodied, reciprocal, and (to a lesser degree) attractive nature of the binary star system. As if spurred on by Beth expressing part of the answer he is trying to convey, Adam invites her to engage in the dance again, this time while standing up.

9 Adam: Exactly, because-I mean, because you-[stands up, extends his arms, and grabs Beth's hands again,
Fig. 8(a), left] because we hold each other here. [they lean outward from each other and stop with their arms fully extended, Fig. 8(a), right]

10 Beth: Mhm. [stays in position with Adam, both of them holding hands with their arms extended]

11 Adam: So even though I weigh more than you, then I will -I couldn't start to rotate around here, [while leaving his hands in place, steps around to the side of Beth again, Fig. 8(b), left] because then you just fall out that way, [points to Beth, then puts hands down] because then there is nothing holding you anymore. [points away from Beth with the thumb of his right hand to the position in the dance across from her, Fig. 8(b), right]

12 Beth: Yeaah. [drops her hands and looks to the IWB]

As Adam leads Beth in the dance a second time, he makes sure to emphasize the normal body position that one would expect in such a dance (i.e., with both participants across from each other with arms extended). In doing so, Adam represents a more authentic version of the dance, pulls more on Beth's hands, and better establishes the spatial orientation he and Beth would inhabit while the dance was taking place. He then acts out the counterfactual scenario again (from lines 4 and 7) by overrotating to a position to Beth's right. As in the first instance of the dance, Adam provides a commentary to the dancing action via talk and gesture. In this way, ROTATING IN A PARTNER DANCE can elicit Beth's embodied intuitions. Adam then highlights specific aspects he sees as relevant to the OP question. This time, he first gestures past Beth to indicate the way that she would "fall out" of the dance and then gestures to the space which he left behind by overrotating where there is "nothing holding [Beth] anymore."

Interestingly, in this way, the dance can be seen as functioning as a coordinating hub [21,31] for Adam and Beth's interaction. The dance elicits a robust, shared embodied image around which the semiotic resources of talk and gesture are used to negotiate and highlight meanings. However, while
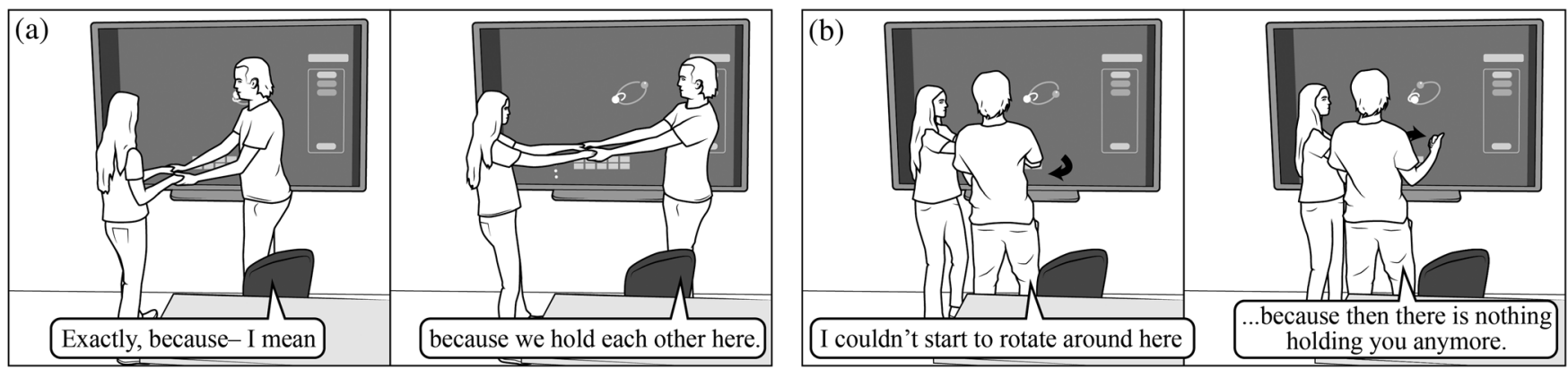

FIG. 8. (a) Adam reengages in the dance with Beth from a standing position (line 9, left frame), this time making sure to draw Beth's attention to the outward position from where the two of them would be holding one another (line 9, right frame). (b) Adam overrotates again (line 11, left frame). He then holds the overrotated position and highlights that "there is nothing left to hold" to Beth while gesturing to the space that he has left unoccupied (line 11, right frame). 


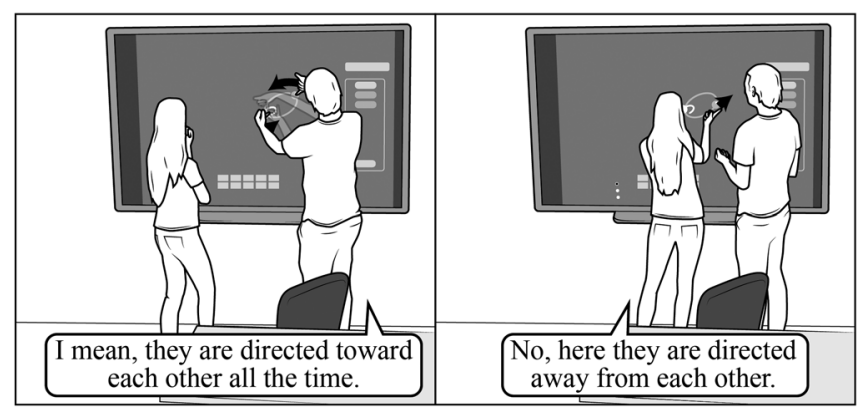

FIG. 9. Adam answers the researchers' question by pointing his fingers inward toward each other as he traces the motion of each star on the IWB (line 13, left frame)-involving the embodied imagery of SYMMETRIC PAIR and ATTRACTION. Beth disagrees and points outward from the center of mass at the apocenters of the orbits (line 14, right frame) — involving the embodied imagery of SYMMETRIC PAIR and REPULSION.

PER studies into the roles of semiotic resources have emphasized the importance of persistent representations $[18,29]$ in the role of coordinating other semiotic resources, we see in the interaction of Adam and Beth that the students can coordinate their meaning making around a nonpersistent, experientially shared embodied image.

After the second dance in lines 9 through 11, Beth responds with a satisfactory "Yeaah" (line 12), as if to indicate that she has finally arrived at an explanation to her OP question which intuitively makes sense. The discussion of binary stars continues through a third and final segment of her and Adam's interaction, wherein we see her express her rationale more explicitly.

\section{Segment 3: A further question}

The third segment of our data begins with an interjection from the researcher, who, after watching the interaction of Adam and Beth with the dance, and in response to their exchange, pushes the two students to strengthen the analogical connection between the dance and the orbiting stars. This is done with the following question: In [the dancing] situation, you are pulling on one another with forces; if you try to imagine force vectors or forces on the objects, how will they be directed and can you see any similarities with-? As the researcher refers to the dance, he extends his arms outward as the students did in the dance. Then, when he refers to the "objects," he points to the stars on the IWB from his seat at the back of the room. Before the researcher can finish the question, Adam answers.

13 Adam: I mean, they are directed toward each other [holds hands up to the IWB and follows both stars as they orbit, pointing his pinky fingers toward each other, Fig. 9, left] all the time. [repeats the motion with his index fingers]

14 Beth: No, here they are directed away from each other. [steps up to the IWB so that Adam has to move and holds her hands over the apocenters of the orbits, pointing her index fingers out from the center, Fig. 9, right]
While Adam responds to the researcher's question correctly, indicating central, inward-directed forces on the IWB (line 13), Beth incorrectly describes the forces as directed "away from each other" (line 14). She answers in a manner consistent with a common perception of an outward force in rotational motion. However, her answer here also highlights one of the possible drawbacks of using the dance as an analogy for the binary star system: by involving her embodied intuitions from a system where she takes on the role of one of the orbiting bodies, she is likely to involve her intuitions which stem from experiencing the non-inertial reference frame. During the dance there is an apparent outward force experienced by the dancers from rotation. To make things worse, when Adam and Beth lean outward from each other in the dance [Fig. 8(a), right], there is a very real (not imagined) torque caused by Earth's gravity which pulls the dancers apart. Further still, the force felt by Adam and Beth in their hands increases as they lean further away from each other. Thus, we see here that the intuitions that accompany the enacted analogy of the dance could be reasonably expected to lead Beth to incorrect conclusions with regards to the binary star system.

Despite the difference in their answers, however, both Adam and Beth gesture with both hands in a radially symmetric manner. The students' expressions suggest an embodied image of a SYMMETRIC PAIR (as in line 1), which in turn aligns well with both $\mathrm{DRA}_{1}$ and $\mathrm{DRA}_{2}$. Adam combines the SYMMETRIC PAIR image with an image of ATTRACTION in a manner which aligns with $\mathrm{DRA}_{4}$. Conversely, Beth combines the SYMMETRIC PAIR image with an image of repulsion.

15 Adam: No.

16 Beth: No? [steps back from the IWB]

17 Adam: Because you can see... [waits for the stars to orbit until they are nearest each other, then pauses the simulation] See, now they are directed like so. [holds his hands over the two stars in the simulation and points his fingers inward, Fig. 10(a), left] That is why they go-go around-*inaudible* [looks at Beth and traces a small circle with his hands on the IWB, Fig. 10(a), right]

18 Beth: Yeaaaah. And then they are directed toward each other, so yeah. [steps up to the IWB and traces the shapes of the orbits while pointing her index fingers toward each other, Fig. 10(b); then Adam presses play]

Though Adam does not explicitly make a connection between the stars on the IWB and the dance, he chooses to pause the simulation at a moment where his inwardpointing fingers most closely resemble the arrangement of two participants' arms during the dance. That is, with the two stars near one another in the simulation, Adam is able to position his fingertips together in a manner which resembles his and Beth's hands moments before. Again, Adam involves the embodied imagery of a SYMMETRIC PAIR along with an image of ATTRACTION. Furthermore, as 

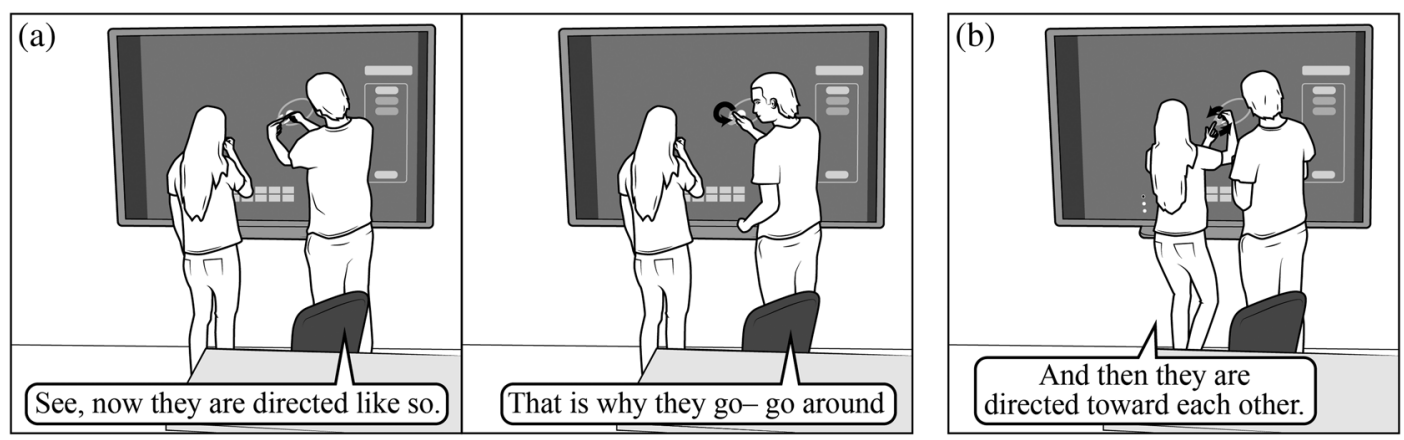

FIG. 10. (a) Adam points his fingers toward each other over the stars on the IWB to show the inward direction of the forces (line 17, left frame). He then gestures in a circular motion while explaining that this is what keeps the stars going "around each other" (line 17, right frame)—which we interpret as involving the embodied image of FORCED AROUND. (b) Beth demonstrates her understanding of Adam's explanation by mirroring his inward pointing gesture against the IWB (line 18). In doing so, she seems to involve the embodied image of ATTRACTION alongside the image of a SYMMETRIC PAIR.

he explains to Beth that the inward direction of the forces is what causes the stars to "go around" while gesturing in a circle on the IWB (line 17), Adam seems to make a connection between the attractive nature of the forces acting on the stars and the overlapping of the orbits traced out by the software. By involving an embodied image which we label again as FORCED AROUND, Adam is once again relating to $\mathrm{DRA}_{3}$. Perhaps surprisingly, the students once again refrain from stating the formal reason that these forces are attractive between the stars (i.e., that the forces are gravitational). Rather, Adam refers informally to the inward direction of forces via the FORCED AROUND embodied image. While it remains untested whether or not bringing up gravity more explicitly would have helped Beth make sense of the binary star dynamics, it appears likely to us that grounding parts of the interaction such as this in familiar formal terminology could have helped cue more explicit and correct reasoning.

In line 18, Beth makes an utterance of her own which involves the SYMMETRIC PAIR image with image of ATTRACTION. Adam presses the play button on the simulation and, in the next line, follows the stars around on the screen with his fingers pointed inward.

19 Adam So here they are directed toward each other [follows the stars as they orbit in the simulation with his fingers pointed toward each other, again, as Beth watches]

20 Beth: Toward each other. Okay.

21 Adam: So... then their forces [points his fingers together in air, Fig. 11(a), left] can be represented [extends his hands toward Beth, Fig. 11(a), right] as our hands, kinda.

22 Beth: Mm.

23 Adam: So, for the two of us to be able to rotate around [points a finger upward in the air and twirls it around in circles while looking at Beth] you have to lean out more than I have to. [points toward Beth, then brings his hands toward his chest to emphasize himself]

24 Beth: I must have a larger orbit! [steps toward the IWB and traces the shape of the larger orbit in the simulation with her index finger while looking at Adam, Fig. 11(b)]

25 Adam: Exactly.

26 Beth: Nice!
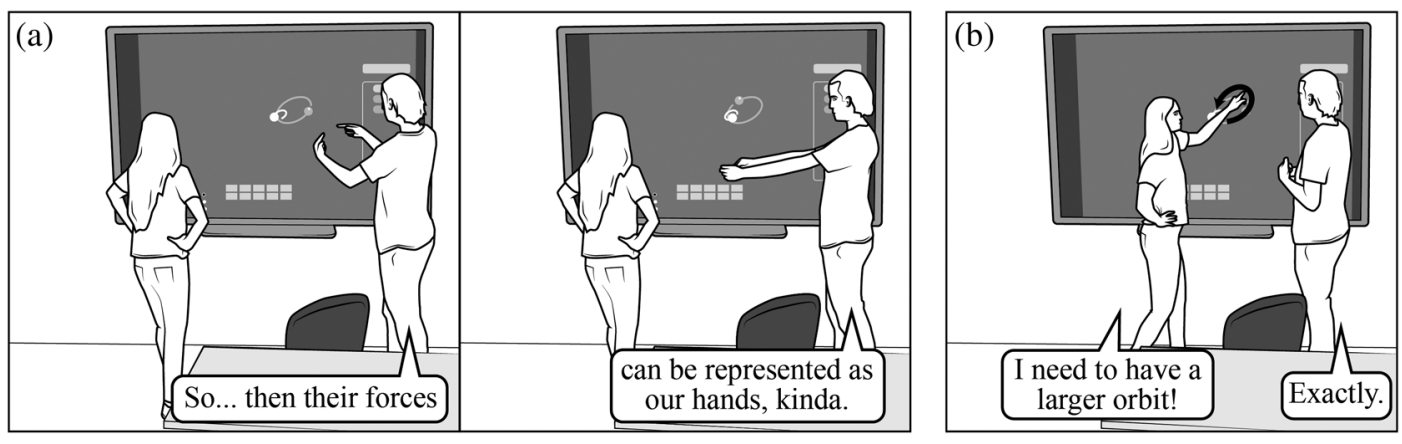

FIG. 11. (a) Adam explicitly links the pointing gesture for the forces of the binary star system (line 31, left frame) with his and Beth's arms during the dance (line 21, right frame) — verbally and gesturally involving ROTATING IN A PARTNER DANCE. (b) Beth gestures along the larger orbit on the IWB while saying that she needs to have a "larger orbit" (line 24), which seems to imply an embodied image of LIGHTER IS FARTHER. 
In this last section of transcript, we finally see Adam make an explicit link between the orbiting stars on the IWB and the dance. He holds his hands out to Beth in a gestural reference to the dance via talk, similar to how Beth did in line 8 , going on to explain that, in the dance, Beth would lean out more than him since he weighs more than her. Thus, Adam is able to elicit the imagery of ROTATING IN A PARTNER DANCE, this time in a nonenacted fashion, as he and Beth have already co-enacted the dance, and thus, shared some common ground [46] in their interaction. Leveraging his mutual experience of the dance with Beth, Adam emphasizes a feature of the dancing which helps to cement the link between the dance and the binary system on the IWB. Adam makes use of the intuitive understanding he and Beth have about how the dance works, in particular, how the experience is different for partners of different mass. Here the embodied imagery of ROTATING IN A PARTNER DANCE seems to be related, in a slightly different manner than before, to Newton's second law and $\mathrm{DRA}_{3}$.

In response to Adam, Beth steps up to the board, traces her finger around the larger orbit (of the less massive star), and excitedly states that she "must have a larger orbit" [Fig. 11(b), line 24]. She chooses words that put her in the role of the star grammatically, suggesting a strong conceptual intermingling of the experiential realm of the dance and astronomical realm of the binary stars. ${ }^{11}$ Similar grammatical use of the first-person pronoun to identify with an external phenomena has been documented in the language of expert physicists [30], which suggests that, to a degree, Beth's utterance can be seen as containing elements of disciplinary discourse. In this way, and for the first time over the course of the entire 2.5-min interaction, we see Beth offer an utterance which suggests an appreciation of why changes in the mass of a star will affect the size of the orbit, but will not make its orbital period fall out of phase with that of the other star. She seems to involve an embodied image of LIGHTER IS FARTHER (which might be the closest of all our identified embodied imagery to a $p$-prim or image schema, i.e., the smallest image) and, like Adam in the line before, this imagery seems to relate well to Newton's second law and $\mathrm{DRA}_{3}$.

At this point of Adam and Beth's interaction, we choose to end our analysis. The two students do continue on after this exchange, but since they are largely satisfied with their discussion and the manner in which they have addressed the OP question, they continue on to explore other features of the My Solar System simulation and other orbital motion situations. As the analysis of the three segments above comprises a lengthy, finer-grained breakdown of the

\footnotetext{
${ }^{11}$ We acknowledge that an analysis which involves conceptual blending [95] could be undoubtedly applied to Adam and Beth's interaction. Nonetheless, with our interest in how Adam and Beth used their bodies to make meaning about astronomy, we prefer to focus on the insights gained from a perspective informed by embodied cognition and social semiotics.
}

2.5-min interaction, we now attempt to "zoom out" and summarize the findings in order to address some of the larger-grained features of Adam and Beth's conversation. We include Fig. 12, a tablelike diagram which comprises the semiotic resources, embodied imagery, and DRAs associated with each line of Adam and Beth's conversation for all three segments of video data analyzed above.

In Fig. 12, one of the first things to note is the progressive incidences of DRAs in Beth's utterances. When she initially asks the OP question at the start of our data, Beth might have been thinking about the complex binary star system in a too holistic way. However, over the course of the entire 2.5-min interaction, she can be seen as producing utterances which collectively express all of the four disciplinary-relevant aspects (admittedly, never involving all four DRAs within a single utterance $^{12}$ ). First in line 8 (Fig. 7), we interpret Beth's utterances as implying $\mathrm{DRA}_{1}, \mathrm{DRA}_{2}$, and $\mathrm{DRA}_{4}$, since she mentions the two stars "holding each other" and gestures to the IWB suggesting an image of HOLDING TOGETHER. The researcher interjects between lines 12 and 13 and the students are explicitly directed to consider the direction of the interaction between the two stars. Following the researcher's question, Beth's utterances imply DRA $A_{1}$, $\mathrm{DRA}_{2}$, and $\mathrm{DRA}_{4}$ again as she gestures against the IWB with an image of a SYMMETRIC PAIR and ATTRACTION (line 18, Fig. 10). Finally, as Beth relates her smaller size to the less massive star in the simulation (line 24, Fig. 11), we interpret her utterance in as implying the last of the DRAs, $\mathrm{DRA}_{3}$, as she talks and gestures at the IWB with an image of LIGHTER IS FARTHER.

This helps us evaluate the worthwhileness of Adam and Beth's informal, disciplinarily unconventional interaction. While it is clear that Adam was, from the beginning, at least implicitly involving all the necessary features (DRAs) for answering the OP question as aligned with the discipline, we can also see how Beth comes to express all of the same features for herself as some evidence of learning. By interpreting the two students' utterances in terms of the implied (and occasionally enacted) embodied imagery, we can value the details of the conversation as fruitful exploration even from a disciplinary perspective.

Another aspect of Adam and Beth's interaction made apparent by Fig. 12 is the evident multiplicity of the semiotic resources within each cell (i.e., the number of semiotic resources used within each line which we see as relating to each DRA). While talk and gesture are frequently used in combination by both Adam and Beth, the "densest" cells are those associated with the dance in lines

\footnotetext{
${ }^{12}$ It, perhaps, should not be surprising that Beth never implies all four disciplinary-relevant aspects in a single utterance, since Adam consistently provides her with utterances that $d o$ include all four disciplinary-relevant aspects and she tends to simply agree with him when he seems to be making sense.
} 


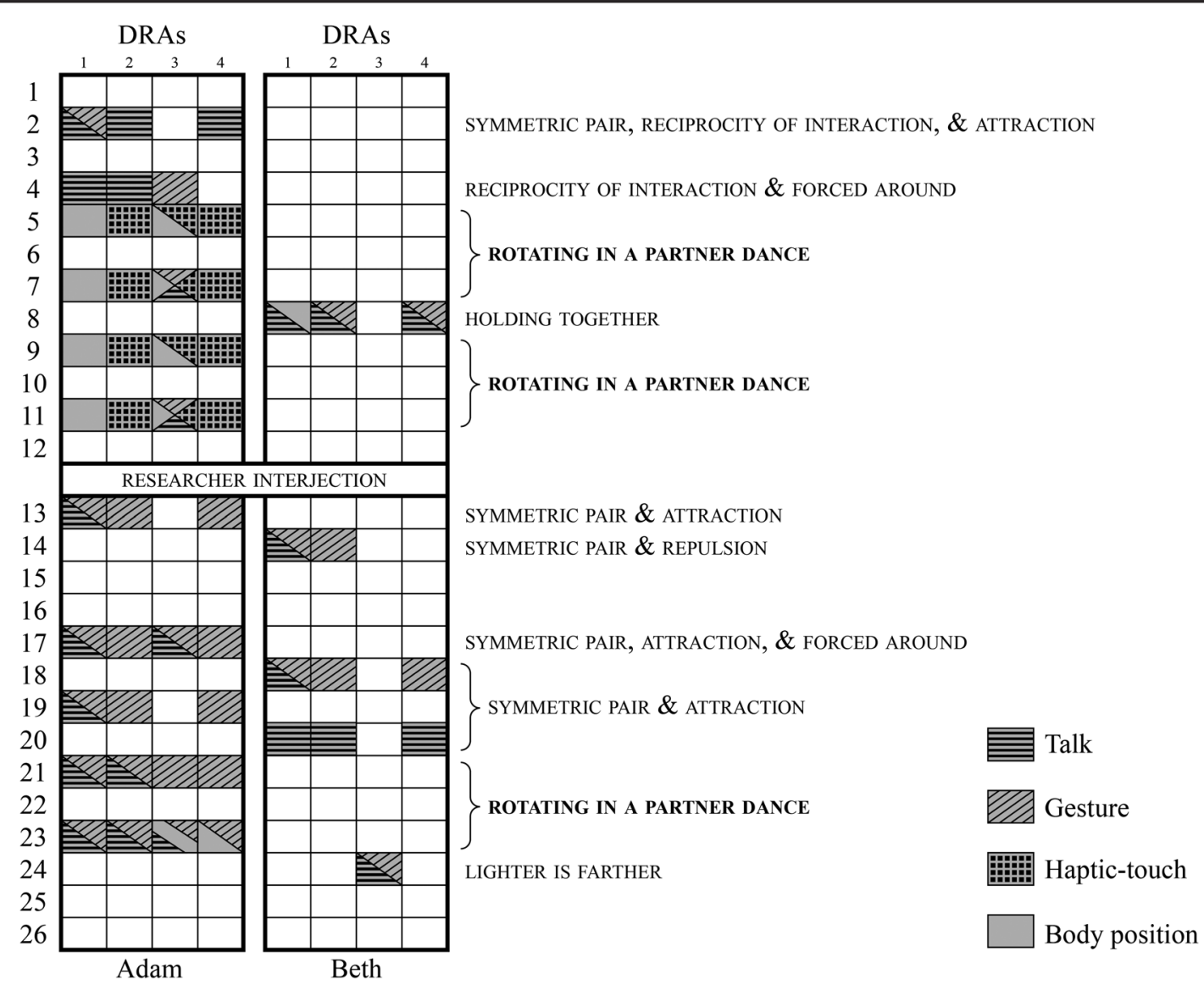

FIG. 12. A line-by-line summary of Adam and Beth's interaction. Each row corresponds to a line of dialogue and each column corresponds to one of the four disciplinary-relevant aspects from the formal treatment of the OP question (recall, DRA 1 states that the interaction requires two bodies, $\mathrm{DRA}_{2}$ states that the interaction is reciprocal, $\mathrm{DRA}_{3}$ states that the interaction determines motion, and $\mathrm{DRA}_{4}$ states that the interaction is attractive). We pattern each cell with the type of semiotic resource utilized by Adam or Beth within that line that we interpret as relating to that disciplinary-relevant aspect. The embodied imagery corresponding to each line is listed to the right.

7, 11, and 23. Each of these lines includes instances of Adam elaborating on the embodied imagery of ROTATING IN A PARTNER DANCE-via a simultaneous layering of three or four of the semiotic resources - to highlight aspects of the dance which we see as related to $\mathrm{DRA}_{3}$. While the multimodal transcript presented throughout this section provides a necessary level of detail to motivate our interpretations of Adam and Beth's interactions, we see that summative tables of student interactions like Fig. 12 could be academically useful in future research for recognizing patterns in students' use of semiotic resources and/or evocation of embodied imagery.

\section{SYNTHESIS AND DISCUSSION}

\section{A. The students' use of nondisciplinary semiotic resources}

The analysis of Adam and Beth's interaction given above allows us to reflect on our research question, stated again here: How do two high school students make use of nondisciplinary meaning-making resources to mechanistically reason about binary star dynamics in ways that relate to aspects deemed relevant by the physics discipline? We answer this question in two parts, highlighting how the students (i) involved their bodies productively and (ii) generated an enacted analogy.

\section{Fruitful embodiment}

In the $2.5 \mathrm{~min}$ of video data analyzed above, Adam and Beth make use of nondisciplinary semiotic resources systems - including talk, gesture, body position, and haptic touch - in a manner which fruitfully involves their embodied intuitions. That is, with a close attention to the ways that Adam and Beth interact via a multimodal ensemble of semiotic resources, we can see educational value in those nondisciplinary semiotic resources. Adam is able to communicate his mechanistic reasoning about the dynamics of binary stars to Beth in a way that encourages her to draw upon her embodied intuitions about rotating in a partner dance. Whether or not Beth has ever participated in this type of dance before, the imagery associated with the dance 
is strong enough that the two students are able to make use of it in their reasoning without actually completing a single turn of the dance during the interaction.

The nondisciplinary semiotic resource systems, particularly the nonverbal semiotic resource systems of body position and haptic touch, make the enactment of a relevant counterfactual (the overrotation in the dance) possible. Adam is then able to talk and gesture around this embodied act to draw Beth's attention to particular features of the situation, thereby resulting in a complex, multimodal utterance which communicates to Beth far more than would be possible with talk alone. We see this observed behavior as consonant with Goodwin's [33] discussion of the way in which talk and gesture can mutually elaborate one another. Our data provide an example of students leveraging many distinct semiotic resources across different semiotic systems in their spontaneous (self-directed) interaction which contribute to the construction of a communicational whole, which goes beyond the parts themselves. Insofar as the physics education community values students' construction of explanatory models for physics phenomena, physics educators should acknowledge the potential for nondisciplinary semiotic resources to leverage students' embodied intuitions in pedagogically fruitful ways.

\section{Generation of an enacted analogy}

As discussed in Sec. I, mechanistic reasoning entails the development of explanatory models. Etkina et al. [13] suggest that "explanatory models are based on analogiesrelating the object or process to a more familiar object or process." This is precisely what Adam and Beth do as they mechanistically reason via nondisciplinary semiotic resources: they generate for themselves an enacted analogy for the orbits of binary stars in the form of an embodied dance.

Haglund and Jeppsson [96] provide a useful discussion on the potential benefits of students' self-generated analogies in the physics classroom, wherein they show how self-generated analogies have the potential to increase students' ownership of learned material $[97,98]$. This seems to be the case particularly when those analogies are taken up in small group discussion $[99,100]$. Heywood and Parker [101] show—and Haglund and Jeppsson's [96] findings support-how the student-generated analogies which involve a high degree of correspondence between the source and the target domains generate rich discussions amongst the students.

We see the emergence of Adam and Beth's enacted analogy as consonant with these findings about students' self-generated analogies. The dance (source domain) corresponds highly_for the purpose of answering the OP question at hand-with the binary star system (target domain) and the students' discussion that surrounds this analogy is certainly rich, as demonstrated by our analysis. Our case highlights how nondisciplinary semiotic resources are a worthwhile component to students' generation of analogies. Haglund and Jeppsson [96] explain that when discussing their own self-generated analogies (rather than when discussing an analogy supplied by a teacher), students are more "aware that the sources are not perfect matches to the targets" and, thus, might be more likely to scrutinize their analogy and explore its limits [96]. With the analysis conducted above, we see nondisciplinary semiotic resources as a potentially necessary piece to students generating and taking up analogies of their own. For example, in line 8 Beth acknowledges that the two stars are attracting each other "in some way" as she gesturally alludes to the dance and the IWB. Beth uses nondisciplinary resources-especially as opposed to involving the concept of gravity directly — as she begins to adopt the analogical link between the dance and the binary star system. Her acceptance of Adam's dancing analogy for the binary stars hinges on her using relatively "loose," informal language alongside gesture and gazebased reference to the simulation on the IWB.

\section{B. Pushing theory forward}

Beyond our reflection on how Adam and Beth utilized nondisciplinary semiotic resources to reason mechanistically about binary stars, we see our study as contributing to theoretical considerations within PER. Namely, in this study we are able to (i) methodologically synthesize two distinct perspectives on embodiment, (ii) provide evidence for nonpersistent hubs around which semiotic resources can be coordinated, and (iii) suggest a further nuancing of the distinction between embodied learning activities (ELAs) and kinesthetic learning activities (KLAs). Each of these topics is discussed below.

\section{Synthesis of perspectives on embodiment}

While there exists research on the ways that the body underlies the metaphorical manner in which we think $[32,40-42,45]$ and research on how the body is used to communicate scientific ideas $[12,33,34,102,103]$, the claims from these perspectives have rarely been combined in the context of concrete physics examples [104] and, for some, have created an immutable divide in what it means to do research of embodiment in learning [105]. Our paper provides a methodology that incorporates the perspectives of embodied cognition and social semiotics into a single analytic framework-something which to our knowledge has not been done before. In doing so, we are able to make inferences about students' reasoning ${ }^{13}$ both as it is

\footnotetext{
${ }^{13}$ While the particular case presented in this paper involves students' mechanistic reasoning, it is worth noting that the methodology developed and used in this study could be expected to be just as useful in cases that do not involve mechanistic reasoning. For example, our approach could have been fruitfully applied to-and was in fact inspired by-datasets that include student engagement that mostly does not involve mechanistic reasoning (e.g., the dataset from Ref. [12]).
} 
comprised of nondisciplinary, embodied semiotic resources and also as it relates to the discipline of physics. The methodological approach used in this paper provides an example of a new analytic approach for those PER scholars interested in the ways that the body is part of students' thinking about, communication around, and learning of physics.

\section{Embodied imagery as coordinating hubs}

Fredlund et al. $[6,31]$ and Volkwyn et al. $[21,106]$ have studied how a persistent semiotic resource (such as diagrams) can serve as a hub for coordinating other nonpersistent resources. In our study, we see examples of this when the students use the content on the IWB screen as a backdrop for gestures. For example, the running simulation in line 13 and the paused simulation in line 17 serve as a persistent representation against which gestures representing forces were layered-akin, also, to what was reported in the study from Ref. [12]. However, we also see that, with the dance, Adam is able to coordinate talk and gesture around the mental image of his and Beth's previous body positions even when they are no longer physically standing in those places. In this way, the image of the dance seems to persist enough for Adam and Beth-even if the persistence is only mental-for the two of them to make meaning around it, similar to how students can make more complex meanings around a persistent ray diagram [31] or a persistent cut-out paper arrow [21]. Thus, with the insights gained from this case study, we might propose an expansion to the socialsemiotic theory in the context of PER: in students' process of meaning making, a good candidate as a hub for the coordination of semiotic resources is a shared embodied image, which persists either physically or figuratively enough to be spoken and gestured around intelligibly. Future research could explore how gestures and body position can demarcate the environment to form semipersistent resources for the anchoring and coordination of nonpersistent semiotic resources. Examples of such demarcation may be found in nondisciplinary resourcesi.e., the locally agreed-upon signs used in Energy Theater [7] (e.g., "jazz hands" for thermal energy) — as well as in conventionalized signs in formal discourse of physicsi.e., the right-hand rule.

\section{ELAs and KLAs}

Our analysis of this case also provides a more nuanced conception of the ways that students' bodies might be incorporated into the learning of physics. Specifically, while Scherr et al. [22] have suggested categorizing physically active learning activities as either embodied (ELAs) or kinesthetic (KLAs), we see the interaction of Adam and Beth as involving features of both categories. Similar to an ELA such as Energy Theater [7,22,23,107], the two students in our case study take on the roles of physical bodies in order to metaphorically act out how they behave; however, similar to how Scherr et al. [22] define a KLA, and as is showcased with the energy-flow-resistance lesson described by Bruun et al. [24], we see the students (particularly Beth) using their bodies as sensors for physical forces and interpreting the sensation of these forces to formulate understandings of physical phenomena on a conceptual level.

This leads us to propose a more general characterization of ELAs as a process of embodying abstract ideas within students' physical bodies and, conversely, KLAs as a process of abstracting inputs from students' physical bodies into more formal conceptions. With such a perspective, the case we present in this paper seems to involve both of these processes simultaneously and continuously. Perhaps, then, effective instances of students learning which involve their bodies necessarily demand both of these ELA/KLA processes in iterative loops. For the interested researcher, our analysis presents an example of embodied learning which seems to subvert an exact placement in either of the ELA or KLA categories exclusively, giving us reason to speculate on how labels of activity such as these might apply to a finer grain size, moment-to-moment account students' embodied interactions. We suggest that, in many of the cases labelled as either KLAs and ELAs, students might actually be continually switching how they use their bodies between "body as a role player" and "body as sensor" in iterative loops as they leverage their bodily intuitions to both embody the abstract, as well as abstract from the body.

\section{Implications for teaching}

The activity in which Adam and Beth participated during this study was framed by the digital tools in the environment and prompts given by the researcher. As discussed in Sec. III, the My Solar System simulation in combination with the IWB effectively shrinks celestial phenomena to human scale (spatially and temporally) [87]. Other studies have shown how such a technological combination elicits a degree of embodied engagement from students $[12,25$, 86,108]. Beyond this, the activity was epistemologically framed [109] as an exploratory, playful activity (both through the open-ended prompt and also, perhaps by the nature of the simulation software itself [90]). Taking the overlap of these two framings (technological and epistemological), we suggest that the activity was set up in a manner which encouraged the students' embodimentrich interaction. While one can expect students' bodies to become involved in physics learning when explicitly requested by their teacher, we propose that open-ended student inquiry activities around large touchscreen interfaces, such as the one studied in this paper, can provide an example of a fertile environment which supports the spontaneous emergence of students' embodied engagement 
in the form of interaction with the technology and each other. It may seem obvious to a teacher that more embodied interaction might take place if students are allowed the space and opportunity to stand in small groups in front of IWBs (as compared to if the same students were required to passively sit in the rows of an auditorium-style lecture hall, or interact sitting behind computer screens). However, our case study shows how the use of interactive technology can lead to student behavior which is productive in unexpected ways. Indeed, a teacher who includes such activities into their classroom may be pleasantly surprised at the embodied engagement of their students. Learning environments spatially set up in ways that allow or even encourage student physical movement also expand the range of possibilities for student active engagement in the learning process. By doing so, such environments may serve to enhance instructional approaches that take active learning [110] and more specifically, collaborative active learning [111] as their guiding principles.

Coming back to the role of the teacher, we recommend that teachers appreciate and become fluent in the nondisciplinary vernacular used during students' informal discussions. Meaning can be made-and consistently is made - in elaborate, multimodal ways. In cases such as ours, students construct meaning in a way which capitalizes on their innate bodily intuitions. Teachers might do well to explicate the connections between student-generated embodied imagery and the relevant aspects of a phenomenon from the physics discipline's perspective. This sentiment is consonant with responsive teaching approaches $[11,85,112,113]$ as well as the valuing of students' selfgenerated resources as compared to those resources presented by a teacher (mentioned in Sec. VA 2). While a teacher could reasonably propose many other semiotic resources for explaining binary star dynamics, encouraging students to come up with their own semiotic resources (and perhaps, especially, those resources which evoke vibrant embodied imagery) can benefit student learning along many dimensions. If Adam and Beth's interaction had occurred in a classroom context with a teacher present, for example, the teacher would do well to encourage the students to relate the intuitive, nondisciplinary explanation that arose with the dance to formal labels. Teaching in this responsive way is one way the teacher can help students make the metaphorical "leap" from intuitive reasoning to terms and mathematical relationships used in the discipline of physics. For a more detailed discussion of how a teacher might respond to students working in the environment presented in this paper, see Rådahl's master's thesis [85].

As a word of caution, it is worth pointing out that the semiotic resource of haptic touch should not be universally encouraged between students. The appropriateness of touch is accepted differently across different sociocultural (and personal) contexts. Factors such as the individuals' ages [114], genders [115], and nationalities [116] seem to impact the degree to which those participants engage in interpersonal touch as well as their interpretation of its appropriateness. Interestingly, the setting in which an interaction takes place also seems to affect when interpersonal touch occurs spontaneously $[114,117,118]$. Nonetheless, and particularly as a caveat to our recommendations in this paper for the benefits of haptic touch in Adam and Beth's interaction, it is important that the respectful treatment of students remains paramount. This includes recognizing that others' comfortability with touch may not reflect one's own.

\section{CONCLUSION}

We have shown how students' coordinated use of nondisciplinary semiotic resources can support mechanistic reasoning about physical phenomena. We have illustrated how two students, Adam and Beth, make use of an embodied analogy in the form of a partnered dance to formulate a response to a question about the orbits of binary stars. In order to analytically address the case at hand, we brought together the ideas of embodied cognition and social semiotics in a new methodological framework and illustrated this framework's utility for studying student interactions during a physics learning activity. In doing so, we add to the growing collection of research that examines the diversity and richness of ways that students recruit meaning-making resources as they reason about physical phenomena, as well as the discussions around cognitive models in physics learning. Moreover, while the technological affordances of the My Solar System simulation and the IWB were not the primary focus of our discussion, we nevertheless provide a detailed account of students working within and around a digitally rich learning environment in disciplinarily fruitful and previously unreported ways.

\section{ACKNOWLEDGMENTS}

The authors would like to thank Jesper Haglund, John Airey, and the rest of the Uppsala PER group for their help editing this paper. We would especially like to thank Cedric Linder for his valuable input and support in writing this paper. We gratefully acknowledge Moa Eriksson for her assistance in ensuring the accuracy of the translations. This project was funded in part through the Swedish VR Grant No. 2016-04113. 
[1] J. Airey, Science, Language, and Literacy: Case Studies of Learning in Swedish University Physics, Ph.D. thesis, Uppsala University, Uppsala, Sweden 2009.

[2] J. Airey and C. Linder, A disciplinary discourse perspective on university science learning: Achieving fluency in a critical constellation of modes, J. Res. Sci. Teach. 46, 27 (2009).

[3] J. L. Lemke, Talking science: Language, Learning, and Values (Ablex Publishing Corporation, Norwood, New Jersey, 1990).

[4] S. Hennessy, Situated cognition and cognitive apprenticeship: Implications for classroom learning, Stud. Sci. Educ. 22, 1 (1993).

[5] J. Airey and C. Linder, Social semiotics in university physics education, in Multiple Representations in Physics Education, edited by D. F. Treagust, R. Duit, and H. E. Fischer (Springer International Publishing, Cham, 2017), pp. 95-122.

[6] T. Fredlund, Using a Social Semiotic Perspective to Inform the Teaching and Learning of Physics, Ph.D. thesis, Uppsala University, Uppsala, Sweden, 2015.

[7] R. E. Scherr, H. G. Close, E. W. Close, V. J. Flood, S. B. McKagan, A. D. Robertson, L. Seeley, M. C. Wittmann, and S. Vokos, Negotiating energy dynamics through embodied action in a materially structured environment, Phys. Rev. ST Phys. Educ. Res. 9, 020105 (2013).

[8] E. F. Redish, Teaching Physics with the Physics Suite (John Wiley \& Sons Inc., Somerset, 2003).

[9] A. B. Arons, A Guide to Introductory Physics Teaching (Wiley, New York, NY, 1990).

[10] E. Etkina, G. Planinsic, and A. Van Heuvelen, College Physics: Explore and Apply, 2nd ed. (Pearson, Upper Saddle River, NJ, 2019).

[11] A. D. Robertson, R. E. Scherr, and D. Hammer, Responsive Teaching in Science and Mathematics (Routledge, New York, NY, 2015).

[12] B. Gregorcic, G. Planinsic, and E. Etkina, Doing science by waving hands: Talk, symbiotic gesture, and interaction with digital content as resources in student inquiry, Phys. Rev. Phys. Educ. Res. 13, 020104 (2017).

[13] E. Etkina, A. Warren, and M. Gentile, The Role of Models in Physics Instruction, Phys. Teach. 44, 34 (2006).

[14] G. Holton and S. G. Brush, Physics, the Human Adventure: From Copernicus to Einstein and Beyond (Rutgers University Press, New Brunswick, NJ, 2005).

[15] PhET, Univ. Colorado, Boulder, https://phet.colorado .edu/en/simulation/legacy/my, 2018.

[16] J. Cameron, Titanic (Paramount Pictures \& 20th Century Fox, 1997).

[17] R. S. Russ, R. E. Scherr, D. Hammer, and J. Mikeska, Recognizing mechanistic reasoning in student scientific inquiry: A framework for discourse analysis developed from philosophy of science, Sci. Educ. 92, 499 (2008).

[18] G. Kress, Multimodality: A Social Semiotic Approach to Contemporary Communication (Taylor \& Francis, New York, NY, 2010).

[19] C. Jewitt, J. Bezemer, and K. O'Halloran, Introducing Multimodality, 1st ed. (Taylor \& Francis, New York, NY, 2016).
[20] T. Fredlund, C. Linder, and J. Airey, A social semiotic approach to identifying critical aspects, Int. J. Lesson Learn. Stud. 4, 302 (2015).

[21] T. S. Volkwyn, J. Airey, B. Gregorcic, F. Heijkensköld, and C. Linder, Physics students learning about abstract mathematical tools when engaging with "invisible" phenomena, Proceedings of the 2017 Physics Education Research Conference, Cincinnati, OH (AIP, New York, 2018), pp. 408-411, http://dx.doi.org/10.1119/perc.2017 .pr.097.

[22] R. E. Scherr, H. G. Close, E. W. Close, and S. Vokos, Representing energy. II. Energy tracking representations, Phys. Rev. ST Phys. Educ. Res. 8, 020115 (2012).

[23] R. E. Scherr, H. G. Close, S. B. McKagan, and S. Vokos, Representing energy. I. Representing a substance ontology for energy, Phys. Rev. ST Phys. Educ. Res. 8, 020114 (2012).

[24] J. Bruun and F. V. Christiansen, Kinesthetic activities in physics instruction: Image schematic justification and design based on didactic situations, NorDiNa 12, 56 (2016).

[25] E. Euler and B. Gregorcic, Exploring how physics students use a sandbox software to move between the physical and the formal, Proceedings of the 2017 Physics Education Research Conference, Cincinnati, OH (AIP, New York, 2018), pp. 128-131, http://dx.doi.org/10 .1119/perc.2017.pr.027.

[26] R. E. Scherr, Gestures as evidence of student thinking about physics, AIP Conf. Proc. 720, 61 (2004).

[27] N. Weliweriya, E. C. Sayre, and D. Zollman, Case study: coordinating among multiple semiotic resources to solve complex physics problems, Eur. J. Phys. 40, 025701 (2019).

[28] T. Fredlund, C. Linder, and J. Airey, Towards addressing transient learning challenges in undergraduate physics: An example from electrostatics, Eur. J. Phys. 36, 055002 (2015).

[29] T. Fredlund, J. Airey, and C. Linder, Enhancing the possibilities for learning: Variation of disciplinaryrelevant aspects in physics representations, Eur. J. Phys. 36, 055001 (2015).

[30] E. Ochs, P. Gonzales, and S. Jacoby, "When I come down I'm in the domain state": grammar and graphic representations in the interpretive activity of physicists, in Interaction and Grammar, edited by E. Ochs, P. Gonzales, and S. Jacoby (Cambridge University Press, Cambridge, England, 1996), pp. 328-369.

[31] T. Fredlund, J. Airey, and C. Linder, Exploring the role of physics representations: an illustrative example from students sharing knowledge about refraction, Eur. J. Phys. 33, 657 (2012).

[32] J. Streeck, C. Goodwin, and C. LeBaron, Embodied Interaction: Language and Body in the Material World (Cambridge University Press, Cambridge, England, 2011).

[33] C. Goodwin, The body in action, in Discourse, the Body, and Identity, edited by J. Coupland and R. Gwyn (Palgrave Macmillan UK, London, 2003), pp. 19-42.

[34] C. Goodwin, Environmentally coupled gesture, in Gesture, and the Dynamical Dimension of Language: 
Essays in Honor of David McNeill, edited by S.D. Duncan, J. Cassell, and E. T. Levy (John Benjamins Publishing Company, Amsterdam, 2007), pp. 195-212.

[35] M. G. Jones, J. Minogue, T. R. Tretter, A. Negishi, and R. Taylor, Haptic augmentation of science instruction: Does touch matter?, Sci. Educ. 90, 111 (2006).

[36] A. Gallace and C. Spence, The science of interpersonal touch: An overview, Neurosci. Biobehav. Rev. 34, 246 (2010).

[37] J. Bezemer and G. Kress, Touch: A resource for making meaning, Aust. J. Lang. Lit. 37, 77 (2014).

[38] L. Crescenzi, C. Jewitt, and S. Price, The role of touch in preschool children's learning using iPad versus paper interaction., Aust. J. Lang. Lit. 37, 86 (2014).

[39] R. Flewitt, N. Kucirkova, and D. Messer, Touching the virtual, touching the real: iPads and enabling literacy for students experiencing disability, Aust. J. Lang. Lit. 37, 107 (2014).

[40] M. Wilson, Six views of embodied cognition, Psychon. Bull. Rev. 9, 625 (2002).

[41] T. G. Amin, F. Jeppsson, and J. Haglund, Conceptual metaphor and embodied cognition in science learning: Introduction to special issue, Int. J. Sci. Educ. 37, 745 (2015).

[42] W.-M. Roth and D. V. Lawless, How does the body get into the mind?, Hum. Stud. 25, 333 (2002).

[43] G. Lakoff and M. Johnson, Conceptual metaphor in everyday language, J. Philos. 77, 453 (1980).

[44] K. Niebert and H. Gropengiesser, Understanding Starts in the Mesocosm: Conceptual metaphor as a framework for external representations in science teaching, Int. J. Sci. Educ. 37, 903 (2015).

[45] K. Niebert, S. Marsch, and D. F. Treagust, Understanding needs embodiment: A theory-guided reanalysis of the role of metaphors and analogies in understanding science, Sci. Educ. 96, 849 (2012).

[46] W.-M. Roth and D. Lawless, Scientific investigations, metaphorical gestures, and the mergence of abstract scientific concepts, Learn. Instr. 12, 285 (2002).

[47] F. Jeppsson, J. Haglund, and T. G. Amin, Varying use of conceptual metaphors across levels of expertise in thermodynamics, Int. J. Sci. Educ. 37, 780 (2015).

[48] A. A. diSessa, Knowledge in pieces, in Constructivism in the computer age, edited by G. E. Forman and P. B. Pufall (Lawrence Erlbaum, Hillsdale, NJ, 1988), pp. 49-70.

[49] A. A. diSessa, Toward an epistemology of physics, Cognit. Instr. 10, 105 (1993).

[50] J. Clement, Creative Model Construction in Scientists and Students (Springer, Netherlands, 2008).

[51] M. Reiner and J. Gilbert, Epistemological resources for thought experimentation in science learning, Int. J. Sci. Educ. 22, 489 (2000).

[52] L. W. Barsalou, Grounded cognition, Annu. Rev. Psychol. 59, 617 (2008).

[53] E. F. Redish, A Theoretical Framework for Physics Education Research: Modeling Student Thinking, Proceedings of the International School of Physics "Enrico Fermi," (Societa Italiana di Fisica, Bologna, Italy, 2004).

[54] D. Hammer, Student resources for learning introductory physics, Am. J. Phys. 68, S52 (2000).
[55] J. Dewey, Democracy and Education: An Introduction to the Philosophy of Education (McMillan, New York, NY, 1916).

[56] M. Merleau-Ponty, Phénomènologie de La Preception (Gallimard, Paris, 1945).

[57] E. F. Redish, Oersted Lecture 2013: How should we think about how our students think?, Am. J. Phys. 82, 537 (2014).

[58] C. Bracikowski, D. Bowman, K. Brown, and R. Madara, Feeling the physics of linear motion, Phys. Teach. 36, 242 (1998)

[59] U. Besson, L. Borghi, A. De Ambrosis, and P. Mascheretti, How to teach friction: Experiments and models, Am. J. Phys. 75, 1106 (2007).

[60] G. Mcsharry and S. Jones, Role-play in science teaching and learning, Sch. Sci. Rev. 82, 73 (2000).

[61] L. C. McDermott, P. S. Shaffer, and M. L. Rosenquist, Physics by Inquiry (John Wiley \& Sons, Inc., New York, NY, 1996), Vol. II.

[62] A. Begel, D. D. Garcia, and S. A. Wolfman, Kinesthetic learning in the classroom, Proceedings of the 35th SIGCSE Technical Symposium on Computer Science Education-SIGCSE'04 (ACM Press, New York, NY, 2004), p. 183.

[63] K. P. Trout and C. A. Gaston, Active-learning physics experiments using the Tarzan Swing, Phys. Teach. 39, 160 (2001).

[64] B. A. Whitworth, J. L. Chiu, and R. L. Bell, Kinesthetic investigations in the physics classroom, Phys. Teach. 52, 91 (2014).

[65] A. J. Richards and E. Etkina, Kinaesthetic learning activities and learning about solar cells, Phys. Educ. 48, 578 (2013).

[66] M. J. Ruiz, Students dance longitudinal standing waves, Phys. Educ. 52, 033006 (2017).

[67] J. Sliško and G. Planinšič, Hands-on experiences with buoyant-less water, Phys. Educ. 45, 292 (2010).

[68] K. Bernhard and J. Bernhard, Mechanics in a wheelchair, Phys. Teach. 37, 555 (1999).

[69] M. H. A. de Oliveira and R. Fischer, Ciênsação: Gaining a feeling for sciences, Phys. Educ. 52, 025011 (2017).

[70] A. Richards, Teaching mechanics using kinesthetic learning activities, Phys. Teach. 57, 35 (2019).

[71] V. P. Coletta, J. Bernardin, D. Pascoe, and A. Hoemke, Feeling Newton's second law, Phys. Teach. 57, 88 (2019).

[72] P. A. G. Sivilotti and S. M. Pike, The suitability of kinesthetic learning activities for teaching distributed algorithms, Proceedings of the 38th SIGCSE Technical Symposium on Computer Science Education SIGCSE'07 (Association for Computing Machinery, New York, NY, 2007), pp. 362-366.

[73] C. A. Morrow, Kinesthetic astronomy: The sky time lesson, Phys. Teach. 38, 252 (2000).

[74] C. A. Manogue, P. J. Siemens, J. Tate, K. Browne, M. L. Niess, and A. J. Wolfer, Paradigms in Physics: A new upper-division curriculum, Am. J. Phys. 69, 978 (2001). 
[75] V. Singh, The electron runaround: Understanding electric circuit basics through a classroom activity, Phys. Teach. 48, 309 (2010).

[76] J. Haglund, F. Jeppsson, and K. J. Schönborn, Taking on the heat - a narrative account of how infrared cameras invite instant inquiry, Res. Sci. Educ. 46, 685 (2016).

[77] J. L. Chiu, C. J. DeJaegher, and J. Chao, The effects of augmented virtual science laboratories on middle school students' understanding of gas properties, Comput. Educ. 85, 59 (2015).

[78] N. Enyedy, J. A. Danish, G. Delacruz, and M. Kumar, Learning physics through play in an augmented reality environment, Int. J. Comput. Collab. Learn. 7, 347 (2012).

[79] M. C. Johnson-Glenberg, D. A. Birchfield, L. Tolentino, and T. Koziupa, Collaborative embodied learning in mixed reality motion-capture environments: Two science studies, J. Educ. Psychol. 106, 86 (2014).

[80] M. C. Johnson-Glenberg and C. Megowan-Romanowicz, Embodied science and mixed reality: How gesture and motion capture affect physics education, Cogn. Res. Princ. Implic. 2, 24 (2017).

[81] I. Han and J. B. Black, Incorporating haptic feedback in simulation for learning physics, Comput. Educ. 57, 2281 (2011).

[82] R. Lindgren, M. Tscholl, S. Wang, and E. Johnson, Enhancing learning and engagement through embodied interaction within a mixed reality simulation, Comput. Educ. 95, 174 (2016).

[83] J. L. Docktor and J. P. Mestre, Synthesis of disciplinebased education research in physics, Phys. Rev. ST Phys. Educ. Res. 10, 020119 (2014).

[84] B. Gregorcic, Exploring Kepler's laws using an interactive whiteboard and Algodoo, Phys. Educ. 50, 511 (2015).

[85] E. Rådahl, Responsive teaching using simulation software: The case of orbital motion, Master's thesis, Uppsala University, Uppsala, Sweden, 2017.

[86] B. Gregorcic, E. Etkina, and G. Planinsic, A new way of using the interactive whiteboard in a high school physics classroom: A case study, Res. Sci. Educ. 48, 465 (2018).

[87] B. Gregorcic and J. Haglund, Conceptual blending as an interpretive lens for student engagement with technology: Exploring celestial motion on an interactive whiteboard, Res. Sci. Educ. (2018).

[88] E. Charters, The use of think-aloud methods in qualitative research: An Introduction to think-aloud methods, Brock Educ. 12, 68 (2003).

[89] See Supplemental Material at http://link.aps.org/ supplemental/10.1103/PhysRevPhysEducRes.15.010134 for a full transcript of the data used in the paper-in a style typical of conversation analysis.

[90] E. Euler and B. Gregorcic, Algodoo as a Microworld: Informally Linking Mathematics and Physics (Accepted), in Mathematics in Physics Education, edited by G. Pospiech (to be published).

[91] J. Bezemer and D. Mavers, Multimodal transcription as academic practice: a social semiotic perspective, Int. J. Soc. Res. Methodol. 14, 191 (2011).
[92] A. Baldry and P. T. Thibault, Multimodal Transcription and Text Analysis: A Multimedia Toolkit and Coursebook (Equinox, London/Oakville, 2006).

[93] L. A. Palinkas, S. M. Horwitz, C. A. Green, J. P. Wisdom, N. Duan, and K. Hoagwood, Purposeful sampling for qualitative data collection and analysis in mixed method implementation research, Adm. Policy Ment. Heal. Ment. Heal. Serv. Res. 42, 533 (2016).

[94] D. Hammer and L. K. Berland, Confusing claims for data: A critique of common practices for presenting qualitative research on learning, J. Learn. Sci. 23, 37 (2014).

[95] G. Fauconnier and M. Turner, Conceptual integration networks, Cogn. Sci. 22, 133 (1998).

[96] J. Haglund and F. Jeppsson, Using self-generated analogies in teaching of thermodynamics, J. Res. Sci. Teach. 49, 898 (2012).

[97] C. Dudley-Marling and D. Searle, Who Owns Learning? Questions of Autonomy, Choice, and Control (Heinemann, Portsmouth, NH, 1995).

[98] M. Milner-Bolotin, The Effects of Topic Choice in Project-Based Instruction on Undergraduate Physical Science Students' Interest, Ownership, and Motivation (The University of Texas at Austin, Austin, TX, 2001).

[99] M. Enghag, P. Gustafsson, and G. Jonsson, Talking physics during small-group work with context-rich problems-analysed from an ownership perspective, Int. J. Sci. Math. Educ. 7, 455 (2009).

[100] M. Enghag and H. Niedderer, Two dimensions of student ownership of learning during small-group work in physics, Int. J. Sci. Math. Educ. 6, 629 (2008).

[101] D. Heywood and J. Parker, Confronting the analogy: Primary teachers exploring the usefulness of analogies in the teaching and learning of electricity, Int. J. Sci. Educ. 19, 869 (1997).

[102] W.-M. Roth and M. Welzel, From activity to gestures and scientific language, J. Res. Sci. Teach. 38, 103 (2001).

[103] R. E. Scherr, Gesture analysis for physics education researchers, Phys. Rev. ST Phys. Educ. Res. 4, 010101 (2008).

[104] F. S. Azevedo and M. J. Mann, Seeing in the dark: Embodied cognition in amateur astronomy practice, J. Learn. Sci. 27, 89 (2018).

[105] R. Stevens, The missing bodies of mathematical thinking and learning have been found, J. Learn. Sci. 21, 337 (2012).

[106] T. S. Volkwyn, J. Airey, B. Gregorcic, and F. Heijkenskjöld, Transduction and science learning: Multimodality in the physics laboratory, Des. Learn. 11, 16 (2019).

[107] A. R. Daane, L. Wells, and R. E. Scherr, Energy theater, Phys. Teach. 52, 291 (2014).

[108] B. Gregorcic, Interactive Whiteboards as a Means of Supporting Students' Physical Engagement and Collaborative Inquiry in Physics, in Selected Papers from the 20th International Conference on Multimedia in Physics Teaching and Learning, edited by L.-J. Thoms and R. Girwidz (European Physical Society, Mulhouse, 2016), pp. 101-108.

[109] T. J. Bing and E. F. Redish, Analyzing problem solving using math in physics: Epistemological framing via 
warrants, Phys. Rev. ST Phys. Educ. Res. 5, 020108 (2009).

[110] D.E. Meltzer and R. K. Thornton, Resource letter ALIP-1: Active-learning instruction in physics, Am. J. Phys. 80, 478 (2012).

[111] D. W. Johnson and R. T. Johnson, Learning Together and Alone, 5th ed. (Allyn and Bacon, Boston, MA, 1999).

[112] L. M. Goodhew and A. D. Robertson, Exploring the role of content knowledge in responsive teaching, Phys. Rev. Phys. Educ. Res. 13, 010106 (2017).

[113] A. D. Robertson, R. Scherr, and D. Hammer, Responsive Teaching in Science and Mathematics (Routledge, New York, NY, 2015).
[114] S. J. Williams and F. N. Willis, Interpersonal touch among preschool children at play, Psychol. Rec. 28, 501 (1978).

[115] D. E. Smith, F. N. Willis, and J. A. Gier, Success and interpersonal touch in a competitive setting, Journal of nonverbal behavior 5, 26 (1980).

[116] E. McDaniel and P. A. Andersen, International patterns of interpersonal tactile communication: A field study, Journal of nonverbal behavior 22, 59 (1998).

[117] D. S. Stier and J. A. Hall, Gender differences in touch: An empirical and theoretical review, J. Pers. Soc. Psychol. 47, 440 (1984).

[118] B. Major, A. M. Schmidlin, and L. Williams, Gender patterns in social touch: The impact of setting and age, J. Pers. Soc. Psychol. 58, 634 (1990). 